\title{
2,5-Dimethyltetrahydrofuran combustion: Ignition delay times at high and low temperatures, speciation measurements and detailed kinetic modeling
}

\author{
Y. Fenard ${ }^{1,2}$, H. Song ${ }^{1}$, H. Minwegen ${ }^{2}$, P. Parab ${ }^{2}$, C. Sampaio Mergulhão ${ }^{1}$, G. Vanhove $^{1}$ and K. A. \\ Heufer $^{2}$ \\ 1 \\ Univ. Lille, CNRS, UMR 8522 - PC2A - Physicochimie des Processus de Combustion et de \\ l'Atmosphère, F-59000 Lille, France \\ ${ }^{2}$ PCFC - Physico Chemical Fundamentals of Combustion, RWTH Aachen, 52602 Aachen, Germany
}

\begin{abstract}
Ignition delays of stoichiometric mixture of 2,5-dimethyltetrahydrofuran $/ \mathrm{O}_{2}$ /inert mixtures were measured at temperatures ranging from 650 to $1300 \mathrm{~K}$ in a RCM and in a shock tube. Operating pressures ranged from 10 to 40 bar at higher temperature (ST) and 10 to 20 bar at lower temperatures (RCM). The ignition delay times exhibit a slight deviation from Arrhenius behaviour, and limited low-temperature reactivity. This behaviour is similar to other cyclic ethers studied in comparable conditions namely THF, 2-MTHF and 3-MTHF, where 2,5-dimethylterahydrofuran (2,5DMTHF) is showing the lowest reactivity of this series of cyclic ethers.
\end{abstract}

Detailed speciation and quantification of the intermediates formed by a stoichiometric 2,5DMTHF $/ \mathrm{O}_{2} / \mathrm{N}_{2}$ mixture in the combustion chamber of the RCM was performed at different times between top dead center and the ignition event for $T_{c}=712 \mathrm{~K}$ and $p_{T D C}=10$ bar. The major fuel specific species observed are 2,5-dimethylfuran, 2,6-dimethyl-1,3-diox-4-ene, hexa-2,5-dione, 1-(2methylcyclopropyl)ethanone, and hex-3-en-2-one.

To provide further insight into the kinetics of the oxidation of 2,5-DMTHF, a comprehensive kinetic model was developed and validated upon the acquired experimental data. Reaction pathway analysis and sensitivity analysis give an overview of the oxidation process of 2,5-DMTHF and elucidates the formation of the experimentally observed fuel-specific intermediates.

Keywords: 2,5-dimethyltetrahydrofuran, ignition delay times, sampling, kinetic modeling, rapid compression machine, shock tube

\section{Introduction}

Starch (as well as sugars), triglycerides and lignocellulose are the general classes of feedstocks derived from biomass used for the production of renewable biofuels and chemicals. Among them, lignocellulosic biomass is the most abundant, and an inexpensive inedible biomass that can be an excellent source of fuels and chemicals without affecting food supplies. Lignocellulose is composed of lignin (15-20\%), which is a three-dimensional methoxylated phenylpropane structure responsible for the structural rigidity of plants and that surrounds hemicellulose $(25-35 \%)$ and cellulose (40-50\%) .

From cellulose, the platform molecule 5-hydroxymethylfurfural (HMF) is yielded by hydrolysis [1]. 2,5-Dimethylfuran (DMF) and 2,5-dimethyltetrahydrofuran (2,5-DMTHF), with high yields of 96.1\% and $94.6 \%$ respectively, were recently produced successfully via green catalytic transfer 
hydrogenolysis of biomass-derived HMF using a nitrogen-doped carbon (NC)-decorated copperbased catalyst with cyclohexanol as hydrogen source [2].

2,5-DMTHF has a superior higher energy density $(35.5 \mathrm{MJ} / \mathrm{kg})$ to ethanol and is immiscible with water. In contrast to 2-methyltetrahydrofuran (2-MTHF) whose lower octane rating may limit its application as a blendstock, 2,5-DMTHF has a RON of 92, making this compound a suitable candidate for a bio-gasoline component [3].

Figure 1: Bond dissociation energies ( $\mathrm{kJ} / \mathrm{mol}$ ) computed by Simmie [3] for THF, 2-MTHF and 2,5-DMTHF (mean values from CBS-QB3, G3 and CBS-APNO methods)

Simmie [3] calculated the reaction rates for all carbon-hydrogen bond dissociation reactions, carbon-methyl bond dissociation reactions and $\mathrm{H}$-atom abstraction reactions by $\mathrm{H}$ atom and methyl radical by using high-level methods for the cyclic ethers, namely G3 and CBS-QB3 methods, showing reasonable consistency (Fig. 1). In addition, the reaction rates for ring-opening reactions of the resulting dimethyltetrahydrofuranyl radicals were investigated. Nevertheless, these reaction rates are mainly relevant to the high temperature oxidation of 2,5-DMTHF. Previous studies on oxolanes have shown evidence of a low temperature reactivity of this compound family without negative temperature coefficient (NTC). The temperature dependence of the reactivity however shows a deviation from Arrhenius behaviour [4-6]. It is expected that the ignition phenomenology of 2,5-DMTHF could be similar to THF and 2-MTHF.

Despite of the work of Simmie [3], the oxidation of the promising 2,5-DMTHF as a gasoline blendstock from biomass is mostly unknown, no detailed kinetic model having been developed. Moreover, no experimental study on the oxidation of 2,5-DMTHF can be found in the literature for validation purposes.

This work proposes an experimental and modeling study of the kinetics of the oxidation of 2,5DMTHF covering the low, intermediate, and high temperature regime of combustion. The pressure dependence on the oxidation of 2,5-DMTHF is also investigated. The ignition delay times of stoichiometric 2,5-DMTHF/O $\mathrm{O}_{2}$ /inert mixtures were experimentally measured in a shock tube and a RCM. In the shock tube facility, ignition delay times under $2 \mathrm{~ms}$ were measured, in a temperature range of 860 to $1330 \mathrm{~K}$, and pressures of 10,20 and $40 \mathrm{bar}$. In the RCM, ignition delay times between 2 and $200 \mathrm{~ms}$ were measured, for temperatures ranging from 650 to $880 \mathrm{~K}$, and pressures between 10 and 20 bar. In order to gain better insight into the low temperature kinetics of 2,5-DMTHF, speciation experiments were performed in conditions relevant to two-stage ignition. A model was built to describe the low and high temperature oxidation of 2,5-DMTHF aiming at an accurate prediction of the ignition delay time and intermediate species mole fraction profiles.

2,5-DMTHF oxidation reaction classes are expected to be similar to THF and 2-MTHF, and presents comparable C-C and C-H BDEs to these two species (Fig. 1). The development of this kinetic model therefore takes advantage of previous modeling efforts describing the oxidation kinetics of THF and 2-MTHF in combustion environments. Three such studies of 2-MTHF were published in 2017 [6-8]. De Bruycker et al. [7] investigated the pyrolysis and combustion chemistry of 2-MTHF. High-level theoretical calculations were used to accurately describe the reactions of 2-MTHF and its derivatives. The resulting model was validated against mole fraction profiles of stable intermediates obtained: in a plug flow reactor at 1.7 bar, temperatures between 900 and $1100 \mathrm{~K}$ and different $\mathrm{N}_{2}$ to 2-MTHF ratios in pyrolysis conditions; in premixed flat flames, for combustion conditions, at $67 \mathrm{mbar}$ and for equivalence ratios of $0.7,1.0$ and 1.3. In addition, laminar burning velocities were measured in 2 
MTHF/air flat flames, for unburnt gas temperatures of 298 to $398 \mathrm{~K}$ and equivalence ratios of 0.61.6, and were compared to simulations from the model. With a homogeneously calculated set of rate constants, the model shows good performance under the conditions of the study. These, however, did not include the low-temperature reactivity of 2-MTHF. The low and high temperature oxidation chemistry of 2-MTHF was however investigated by Tripathi et al. [8]. Ignition delay times of 2-MTHF/oxidizer/diluent mixtures were measured in a rapid compression machine and in a shock tube, covering temperatures from 639 to $1413 \mathrm{~K}$, pressures of 10, 20 and 40 bar and equivalence ratios of $0.5,1$ and 2 . A kinetic model describing both low and high temperature regimes was built and was validated against the measured ignition delays, as well as already existing flame species profiles. The development of the model was based on analogies with THF when the reaction rates were available and complemented by optimized rates for alkanes. More particularly, the lowtemperature sub-mechanism describing the oxidation of 2-MTHF at low temperatures was developed systematically based on rate rules and reaction classes [9]. The ignition delays of stoichiometric 2-MTHF/O $\mathrm{O}_{2} /$ inert mixtures were measured by Fenard et al. [6] for pressures ranging from 3 to 21 bar and core gas temperatures between $640 \mathrm{~K}$ and $900 \mathrm{~K}$. Two-stage ignition was pointed out. Detailed speciation of the reacting mixture in the chamber of the RCM was carried out for different times between the end of compression time and the total ignition. The resulting mole fraction profiles of the stable oxidation intermediates and the ignition delays were used to validate a model built during this study. The model development relies on a similar process as described for Tripathi et al. [8], namely based on rate rules and reaction classes existing for alkanes [10] and optimized. The model shows good performance for the prediction of first stage and total ignition delays, and good agreement with experimental sampling data. The most recent modeling effort concerning the low temperature regime [5] of the oxidation of THF is based on theoretically calculated rate constants. Thermochemical and kinetic data related to the most important elementary reactions have been derived from ab initio calculations at the CBS-QB3 level of theory. It is important to stress that a comparison of the rate constants at $600 \mathrm{~K}$, obtained from these calculations with values estimated using recently published rate rules for alkanes, sometimes show differences of several orders of magnitude for alkylperoxy radical isomerizations, $\mathrm{HO}_{2}$-eliminations, and cyclic ether formation reactions. This model satisfactorily reproduces previously published ignition delay times obtained in a rapid compression machine and in a shock tube, as well as numerous product mole fractions measured in a jet-stirred reactor at low to intermediate temperatures and in a low-pressure laminar premixed flame.

\section{Experimental setup}

\subsection{Shock tube experiments}

Ignition delay time (IDT) measurements behind reflected shock waves were performed in the PCFC shock tube, which has been described in detail previously [11,12]. Briefly, the stainless steel shock tube is composed of a $3 \mathrm{~m}$ long curved driver section and a $4.1 \mathrm{~m}$ driven section with a constant inner diameter of $63.5 \mathrm{~mm}$. A double diaphragm chamber is separating the two sections, housing up to two pre-scored aluminium diaphragms.

The incident shock velocities were measured over the last meter before the closed end of the driven section using five PCB $113 \mathrm{~B} 22$ pressure transducers. The pressure recordings were used during the post processing for the determination of the shock velocity. With this information the shock equations were solved as implemented in the shock and detonation package toolbox [13] developed for Cantera [14] to determine the gas conditions behind the reflected shock. In these calculations the shock equations were treated ideally, assuming the chemistry as frozen, whereas the gas states were determined based on the thermodynamic data implemented in the current model, assumed to 
be thermodynamically equilibrated behind the shock waves. Herein, the ignition delay time is defined as the time interval between the pressure rise of the reflected shock and the steep pressure rise corresponding to ignition at the measuring position closest to the endwall ( $9 \mathrm{~mm}$ ) (Fig. 2).

Figure 2: Example pressure trace presenting the IDT definition in the shock tube

2,5-DMTHF in air mixtures were prepared in a heated Teflon coated stainless steel mixing vessel with a volume of $40 \mathrm{~L}$. The mixtures were prepared with the aid of two static pressure sensors (STS 1st 0500 mbar, STS 1st 0-10 bar), which monitored the partial pressures required for the mixtures. For the shock tube measurements stoichiometric fuel in air mixtures were targeted, leading to $2.41 \%$ 2,5-DMTHF in an air-like composition of $\mathrm{N}_{2} / \mathrm{O}_{2}=79 / 21$. Oxygen and nitrogen are added after vaporizing the fuel into the mixing vessel. Both the oxygen and the nitrogen were obtained from Westfalen AG with $99.999 \%$ purity. Two kinds of 2,5-DMTHF were considered for this study in the shock tube: Butylated hydroxytoluene (BHT), ca. 300 ppm, stabilized 2,5-DMTHF with 99.8\% purity of 1:1 cis/trans-DMTHF mixture from TCl and stabilizer-free 2,5-DMTHF with > 96\% purity from Sigma-Aldrich. The measurements of the IDTs with both mixtures revealed no significant deviation in reactivity, as can be seen in the Supplementary Material. After preparation, a mixing time of 60 min was allowed in order to ensure homogenous mixing. A preliminary study of the effect of the mixing time showed that no effect on the ignition delay was visible already after 15 minutes. To avoid condensation of the fuel, the driven section, diaphragm chamber, mixing vessel and all connecting tubes were heated constantly to $40^{\circ} \mathrm{C}$ during the whole measurement and mixture preparation procedure.

Taking into account possible uncertainties in the measurement of the initial temperatures and pressures, the shock velocities and the thermodynamic data of the fuel-air mixture the uncertainties in the conditions behind the reflected shock have been estimated to $\pm 0.8 \%$ in temperature and \pm $1.5 \%$ in pressure $[11,12]$. Due to the uncertainties involved in the shock tube process, typically a scatter of the ignition delay times of $\pm 20 \%$ is observed [15] and assigned as an uncertainty range in this study.

Furthermore, the shock tube also shows a non-ideal behavior at longer ignition delay times due to the boundary layers and non-ideal opening of the diaphragms that constitute to a constant rate of pressure rise as a function of time (dp/dt). The constant pressure rise leads to a temperature increase, thereby reducing the ignition delay time from its ideal behavior. An averaged constant pressure rise of $8 \% / \mathrm{ms}$ was considered for the measurements taken with respect to this study (Fig. 2).

\subsection{RCM experiments}

The ULille RCM was used for ignition delay measurements of 2,5-DMTHF under low-to-intermediate temperature conditions and the speciation experiments of the fuel and stable intermediates. The apparatus' detailed design and characteristics have been addressed in previous bibliography $[6,16]$, therefore only a brief explanation will be given here.

Compressed air pushes the driving piston and the connected guide cam, which propels the driven piston inside the combustion chamber. The shape of the cam holds the driven piston still at its position after the compression stroke, which prevents piston rebound during the ignition delay period. The combustion chamber was heated and maintained at $90^{\circ} \mathrm{C}$ by electric wall heaters, with a maximum deviation of $1^{\circ} \mathrm{C}$ along the axial direction, and the pressure history was recorded by a piezoelectric pressure transducer protected from thermal shock (Kistler 601CA) and a charge 
amplifier (Kistler 5007). The adiabatic core assumption is used to calculate the compressed gas temperature, which also means that different core gas temperatures $T_{C}$ could be reached by varying the inert gas composition of the mixture-namely $\mathrm{N}_{2}, \mathrm{Ar}$, and $\mathrm{CO}_{2}$-while maintaining the inert-tooxygen ratio of $79 / 21$. It leads to $1.5-2^{\circ} \mathrm{C}$ difference for the compressed core gas temperature per $1^{\circ} \mathrm{C}$ of change on the initial gas temperature prior to compression, depending on the inert gas composition. Hence, while conducting at least 3 repeated RCM experiments on a given initial condition, efforts have been made to minimize the deviation of the initial gas temperature which eventually results in minimum scatter of experimental data points at every core gas temperature condition. Along with this, a creviced piston is used to absorb the developing boundary layer during compression, in order to suppress the roll-up vortex and preserve the homogeneity of the temperature field inside the combustion chamber [17].

Different mixtures were prepared in glass vessels following the partial pressure method, and brand new stabilizer-free 2,5-DMTHF (mixture of cis- and trans-, Sigma-Aldrich, >96 \%) was treated by repeated freeze-thaw purification processes to remove eventual dissolved gases. All the gaseous components were supplied by Air Liquide with over $99.99 \%$ purity. Finally, 14 different mixtures varying in their inert composition were prepared and used to measure the first stage and total ignition delay of 2,5-DMTHF $/ \mathrm{O}_{2} /$ inert mixtures at stoichiometry, for $\mathrm{T}_{\mathrm{C}}=639-866 \mathrm{~K}$ and $\mathrm{p}_{\mathrm{TDC}}=5-20$ bar conditions. The first stage ignition event timing was determined from the maximum $\mathrm{CH}_{2} \mathrm{O}^{*}$ emission profiles recorded using a photomultiplier equipped with a $400 \mathrm{~nm}$ band pass filter for top dead center pressures $\mathrm{p}_{\mathrm{TDC}}=15$ bar and less, and from the maximum derivative of the pressure associated with this event at higher pressures. As observed in the case of other oxolanes $[4,6]$, the pressure jump associated with first-stage ignition is very faint, leading to increased scatter in the first-stage ignition delay data when the first-stage ignition event was determined from the pressure profile. The total ignition event timing was defined as the maximum derivative of the pressure corresponding to ignition at all pressures.

Speciation of the stable intermediates was performed to investigate the specific low-temperature oxidation pathways of 2,5-DMTHF. The conditions are $T_{c}=710 \mathrm{~K}, \mathrm{p}_{\mathrm{TDC}}=10$ bar and equivalence ratio $=1$. In this case, the first stage ignition delay was $24 \mathrm{~ms}$ and the total ignition delay was $44 \mathrm{~ms}$. Each sample was extracted at a different time within the ignition delay period, i.e. from the end of compression until the autoignition, thus the temporal evolution of intermediate species could be measured. Figure 3 depicts an example of pressure history during the sampling experiment in comparison with typical reacting and non-reacting profiles.

Figure 3: Pressure profiles for 2,5-DMTHF $/ \mathrm{O}_{2} / \mathrm{N}_{2}$ stoichiometric mixtures, $p_{T D C}=10$ bar and $T_{C}=710 \mathrm{~K}$ in the ULille RCM. Continuous black line: Reactive pressure history; Dashed line: example of pressure profile during sampling experiments; Short-Dashed line: Non-reactive pressure history; Blue line: Simulated pressure history; Red continuous line: $\mathrm{CH}_{2} \mathrm{O}$ * chemiluminescence captured with a PM filtered around $400 \mathrm{~nm}$.

Sampled mixtures were then analyzed with a Bruker Scion 456-GC gas chromatograph equipped with HP5 and Bond Q columns coupled with FID/TCD and mass spectroscopy detectors for hydrocarbons, and an Agilent 6890 gas chromatograph equipped with a molecular sieve and coupled to TCD/FID detectors for permanent gases and $\mathrm{CO}$. Calibration factors for propane, $n$-butane, 2-methylpropane, $n$-hexane, propene, 1,2-propadiene, 2-propenal, 2-butenal, 3-buten-2-one, acetaldehyde, acetone, 2-butanone, methanol, 2,5-dimethyltetrahydrofuran and carbon monoxide were measured from standard mixtures as well as in-house prepared mixtures from pure products. The concept of effective carbon number [18] was used to obtain the FID calibration factors for the compounds that were not commercially available. The uncertainty on the reported mole fractions was estimated to 
be $5 \%$ in the case of measured calibration factors and $10 \%$ when the effective carbon number method was used [6].

\section{Computation methods}

\subsection{Thermodynamic data}

The C0-C4 species thermodynamic parameters were taken from the AramcoMech2.0 [19] base mechanism. Thermodynamic properties of the species included in the developed submechanism were estimated using the THERM [20] software. THERM uses Benson's group additivity principles [21] and tabulated values for bond strengths, changes in entropy, and loss of vibrational degrees of freedom to estimate properties for radical species from parent molecules. In order to increase accuracy for target species of this study, thermodynamic contributions for selected groups were updated, using relevant data published by Dorofeeva et al. [22] for ring corrections in the case of cyclic ethers, and by Bugler et al. [23] for groups relevant to low temperature chemistry.

Nevertheless, because of the importance of the thermodynamic parameters in the estimation of the reverse rate constants of equilibria, these properties should be determined with particular care in the case of the reactants and products of the most sensitive reactions. The reactivity at lower temperatures strongly depends on the addition of fuel radicals on molecular oxygen, and on its counterparts. Ab-initio calculations were therefore performed to derive thermochemical data for the fuel, the three primary fuel radicals and 41 radicals and intermediate species relevant to low temperature oxidation chemistry.

Herein, a G4 composite method [24], implemented in the gaussian09 package [25] for computing thermodynamic properties of interest is applied. The accuracy of enthalpies of formation calculated from this method has been tested on the G3/05 test set (which includes 270 datasets) and was shown to be $0.83 \mathrm{kcal} / \mathrm{mol}$ [26]. Also Somers and Simmie [27] suggested within their benchmark study of different compound methods to use G4, when applying just one single compound method for enthalpies of formation. To reproduce enthalpies of formation with the G4 results, the atomization approach suggested by Saeys et al. [28] was employed. The use of another approach, isodesmic reactions for example, was shown to lead to larger deviations. In comparison to enthalpies of formation calculated by Simmie [3] for the trans- and cis- forms of 2,5-DMTHF using the compound methods G3, CBS-QB3 and CBS-APNO, minor deviations were found, below $0.5 \mathrm{~kJ} / \mathrm{mol}$ to the current results of the $\mathrm{G} 4$ level of theory.

A detailed description of the used approach for thermodynamic properties determination can be found in [29]. Briefly, temperature dependency of thermodynamic properties (e.g. enthalpy, heat capacity and entropy) is derived from Rigid Rotor Harmonic Oscillator (RRHO) canonical partition functions corrected for rotational hindrance potentials of internal rotating groups at bonds of bond order smaller than two. Rotational potential scans (c.f. Supplementary Material), frequency calculations and geometries are obtained at B3LYP / 6-31G(2df,p) level of theory, which also is applied for the calculation of equilibrium structures and harmonic frequencies within the G4 compound method itself. These results and the calculated G4 standard heats of formation feed into the mentioned statistical thermodynamics methods, which are implemented in TAMkin [30] to derive the temperature dependent enthalpy, entropy and heat capacity of the different species. NASA polynomial coefficients are fitted to the results between 100 and $5000 \mathrm{~K}$, with a fixed separation of the high and low temperature regime at $1000 \mathrm{~K}$. 


\subsection{Reaction rate constants}

\subsubsection{General features}

AramcoMech2.0 was chosen in this model development for the base mechanism. It has been developed in a hierarchical way along with a systematic validation against a large array of experimental measurements including data from shock tubes, rapid compression machines, flames, jet-stirred and plug-flow reactors: starting with a $\mathrm{H}_{2} / \mathrm{O}_{2}$ sub-mechanism [31], followed by a $\mathrm{C} 1$ submechanism [32] and has grown to include larger carbon species [19]. On top of this base, a submechanism describing the oxidation of 2,5-DMTHF was implemented. The complete model is available in supplementary materials. A file containing the names of species as written in the submechanism for 2,5-DMTHF along with their molecular structure is available in supplementary materials.

\subsubsection{High temperature model for 2,5-DMTHF}

In the following, the choices of reaction rate parameters employed in the high temperature submechanism of 2,5-DMTHF are explained. The reaction numbers refer to tables in supplementary materials. Carbon-hydrogen unimolecular dissociation reactions lead to the formation of three primary radicals of 2,5-DMTHF, i.e. 2,5-dimethyltetrahydrofuran-1-yl (DMTHF1J), 2,5dimethyltetrahydrofuran-2-yl (DMTHF2J), and 2,5-dimethyltetrahydrofuran-3-yl (DMTHF3J) where the letter $J$ expresses the existence of a radical and the number describes its position on the molecule (Fig. 1). Reaction rate coefficients are associated with reaction rate coefficients from Atef et al. [33] in analogy with isooctane. In order to express the effect of the lower BDE for $\mathrm{C2}-\mathrm{H}$, the activation energy for reaction 2 was decreased by $4 \mathrm{kcal} / \mathrm{mol}$. The reaction rate coefficients for the carbon-methyl bond dissociation was taken from the work of Simmie [3]. In order to obtain a better match between simulated and experimental ignition delays at higher pressures, the $A$ factor is divided by a factor of 2 and $1 \mathrm{kcal} / \mathrm{mol}$ is retrieved from the activation energy, which is within the claimed uncertainty of the calculation. The reaction rate coefficients for the decomposition reactions of 2,5-DMTHF by carbene and biradical pathways are based on analogies with 2-MTHF [7].

Reaction rate coefficients for bimolecular initiation reactions are taken from a 2-MTHF mechanism [6]. The $\mathrm{H}$-atom abstraction reaction rate coefficients by $\dot{\mathrm{H}}$ atom and methyl radicals were calculated for 2,5-DMTHF [3]. $\mathrm{H}$-atom abstraction reactions by $\dot{\mathrm{OH}}, \dot{\mathrm{O}}, \mathrm{HC} \mathrm{O}$ and $\mathrm{CH}_{3} \dot{\mathrm{O}}$ radicals were also considered and the corresponding rate coefficients are taken from calculations by De Bruycker et al. [7] for 2-MTHF. The reaction rate coefficients of the $\mathrm{H}$-atom abstraction reactions by $\mathrm{CH}_{3} \mathrm{O}_{2}$ from 2,5DMTHF were approximated as being equal to the $\mathrm{H}$-atom abstraction reaction rate coefficients by the $\mathrm{CH}_{3} \mathrm{O}_{2}$ radical from iso-octane [33]. The theoretical calculation work from Chakravarty et al. [34] was used for assigning the coefficients of $\mathrm{H}$-atom abstraction reaction by $\mathrm{HO}_{2}$, initially provided for 2-MTHF.

The reaction rate coefficients of ring opening reactions $37,39,42,46,48$ and 50 were calculated for 2,5-DMTHF [3]. The pre-exponential factor of reaction 42 was reduced by a factor of 2 within the theoretical calculation uncertainty. The beta-scission reaction rate coefficients of the product of reaction 42 were taken from [7]. Other ring opening reaction rate coefficients are not modified. The primary radicals of 2,5-DMTHF can decompose into unsaturated cyclic ethers (R. 52-55) by C-H or C$\mathrm{C}$ bond dissociation reactions whereby the rate coefficients are estimated to be the same as for 2MTHF [7]. The resulting dimethyldihydrofurans can further react by $\mathrm{H}$-atom abstraction reactions. For estimating rate coefficients analogy with 2,5-DMTHF [7] for C2 tertiary carbon position (R. 56-63) or with but-1-ene, to reflect the allylic carbon position [19] (R. 64-71), are used. Other reaction rate coefficients for dimethyldihydrofurans and their radicals deduced from analogies with THF [5] (R. 7281). The behaviour of 5-methyl-2,3-dihydrofuran isomerizing into cyclopropyl ketone and methyl 
propenyl ketone was described by Dubnikova et al. [35]. An analogy is made in this work with a similar system (R. 90-92).

It is expected that the oxidation of DMTHF could lead to the formation of DMF (dimethylfuran), MF (methylfuran) and furan, which is confirmed experimentally. The consumption of these furanic compounds was described in the model by unimolecular decompositions and addition of $\mathrm{OH}$ radicals on the furanic cycle by analogy with furan [5].

\subsubsection{Low temperature model for 2,5-DMTHF}

The model formulation for the oxidation of 2,5-DMTHF in the low temperature takes up the general scheme for alkanes [36]. However, it has been demonstrated that the reaction rates for a class of reactions may differ by several order of magnitude between an alkane and a cyclic ether [5]. Figure 4 summarizes the low-temperature reaction classes taken into account in this work.

Figure 4: Low temperature reaction pathways considered for the model formulation of 2,5-DMTHF

Briefly, the fuel, denoted by $\mathrm{RH}$, undergoes $\mathrm{H}$-atom abstraction reactions forming the primary radicals $\dot{R}$. Then, an addition reaction of $\dot{R}$ on molecular oxygen yields a peroxyl radical, $\mathrm{RO}_{2}$, followed by an internal $\mathrm{H}$ atom transfer giving a hydroperoxyl radical $\dot{\mathrm{Q} O O H}$. $\mathrm{RO}_{2}$ can produce an unsaturated counterpart to $\mathrm{RH}$ by concerted elimination of $\mathrm{HO}_{2}$. This unsaturated counterpart is also produced from $\mathrm{Q} \mathrm{OOH}$ by $\mathrm{HO}_{2}$ elimination. $\mathrm{Q} O O H$ further reacts through cyclic ether formation, betascission, or a second addition on $\mathrm{O}_{2}$ that forms $\mathrm{OOQOOH}$. Then, the sequence described after the first addition to $\mathrm{O}_{2}$ can be repeated. Nevertheless, in this model, only the branching through the $\mathrm{O} \mathrm{OQOOH}=$ ketohydroperoxide $+\dot{\mathrm{OH}}$ pathway (Pathway I, Fig. 4) is considered and not a further addition to $\mathrm{O}_{2}$ [37] that relate to longer alkyl chains. This is justified by the fact that ketohydroperoxide formation is favored thanks to the lowered BDE of the $\mathrm{C}-\mathrm{H}$ bond involved in the $\mathrm{H}$-atom shift during the reaction. However, due to the structure of 2,5-DMTHF, the formation of a ketohydroperoxide is not possible in the case of the DMTHF2J radical leading to a dead-end when the preferential $\mathrm{OOQOOH}$ is formed as described in Fig. 5._During the formulation of this model, pathway II was therefore implemented for the DMTHF2J radical. It takes into account the intramolecular $\mathrm{H}$ atom transfer that produces the $\mathrm{HOOPOOH}$ class radicals. As consumption pathways for $\mathrm{HOOPOOH}$ the formation of a hydroperoxyl cyclic ether and $\mathrm{OH}$ radical as well as the formation of the hydroperoxyl unsaturated counterpart and $\mathrm{HO}_{2}$ radical and their subsequent decomposition were added.

In the next paragraph the choices of reaction rate coefficients employed in the low temperature submechanism of 2,5-DMTHF are explained. Miyoshi et al. [37] calculated the reaction rates for the addition of butanyl radicals on $\mathrm{O}_{2}$ for different isomers. With respect to the structure of 2,5-DMTHF, analogies were made between DMTHF1J and butan-1-yl radical, DMTHF3J and butan-2-yl radical and DMTHF2J and 2-methylbutan-2-yl radical (R. 93-95). In the last case the reaction rate of the addition of DMTHF2J to $\mathrm{O}_{2}$ is divided by a factor of 3 because of the oxygen of 2,5-DMTHF molecule is in alpha position with respect to the oxygen in the furan ring. In the case of concerted elimination reactions of $\mathrm{HO}_{2}$ from $\mathrm{RO}_{2}$, the reaction rates from the THF mechanism by Fenard et al. [5] were adopted. The 2,5-dimethyldihydrofurans formed are named, in the mechanism, with an $\mathrm{X}$ that denotes the double bond with a number before for the positions of the $\mathrm{C}-\mathrm{C}$ bond concerned (i.e. DMTHF1X, DMTHF2X and DMTHF3X). The variations in the structure between THF and 2,5-DMTHF required modification of the activation energy of $-2 \mathrm{kcal} / \mathrm{mol}$ in the case of a tertiary carbon and +2 
$\mathrm{kcal} / \mathrm{mol}$ for a primary carbon bonded to the eliminated $\mathrm{H}$ atom [8]. The reaction rate coefficients for isomerization reactions of $\mathrm{RO}_{2}$ into $\mathrm{QOOH}$ were taken from the work of Parab et al. [38], calculated for 2-MTHF. Analogies with the reaction rate coefficients used for the model of THF [5] were adopted for the reactions of hydroperoxyl radical elimination from $\mathrm{Q} O O H$, formation of a cyclic ether and $\dot{\mathrm{OH}}$ radical, beta-scission of $\dot{\mathrm{O} O O H}$ radical, and molecular rearrangement forming a dioxene molecule and an $\mathrm{OH}$ radical.

The second addition to $\mathrm{O}_{2}$ leads to the formation of 15 different $\mathrm{OOQOOH}$ radicals, and was described using the same reaction rate coefficients as described for reactions 93-95, but decreased by a factor of 2 . Concerning the reactions of $\mathrm{OOQOOH}$ radicals giving dimethylhydroperoxydihydrofuran $+\mathrm{HO}_{2}$ radical, the same reaction rate coefficients as for the concerted elimination reactions of $\mathrm{RO}_{2}$ towards an alkene and $\mathrm{HO}_{2}$ (reactions 96-100) were used.

For pathway I (Fig. 4), the reaction rate coefficients adopted for the reaction $\mathrm{OOQOOH}=$ ketohydroperoxide $+\dot{\mathrm{OH}}$ are the one used for reactions of isomerization 102-116. A reduction of the activation energy of $-2 \mathrm{kcal} / \mathrm{mol}$ was considered in order to account for the weaker bond of the $\mathrm{H}$ $\mathrm{COOH}$ group in $\mathrm{OOQOOH}$. The reaction rate coefficients of the thermal decomposition of ketohydroperoxide come from an analogy with the propan-2-yl radical [39].

In pathway II (Fig. 4), ȮOQOOH radicals isomerize into $\mathrm{HOOPOOH}$ radicals. Reaction rate coefficients were set in analogy with reactions 102-116. HOOPOOH radicals then either yield hydroperoxy cyclic ether and an $\mathrm{OH}$ radical, with reaction rate coefficients as R. 122-126, or undergo a hydroperoxyl radical elimination, with rate coefficients as for R. 117-121. The reaction rate for the decomposition reactions of hydroperoxy cyclic ether and hydroperoxy dihydrofurans was chosen identical as for ketohydroperoxides [8].

Also, degenerate chain branching reactions are added with respect to the reaction classes employed for the modeling work on 2-MTHF [8]. H-atom abstraction from the fuel by alkyl peroxy radical were added in order to complete this submechanism with reaction rate coefficients taken from the work on iso-octane by Atef et al. [33].

Finally, because the radical 2-hexanon-5-yl $\left(\operatorname{CCJCCC}\left({ }^{*} \mathrm{O}\right) \mathrm{C}\right)$ is the major beta-scission product of the favored DMTHF2J primary radical, the rules of modeling the low temperature chemistry were applied.

The complete kinetic mechanism with the corresponding thermodynamic data file is provided in Supplementary materials.

\subsection{Computation methods}

Ignition delay times in shock tube conditions were computed with the homogeneous closed reactor configuration. In this configuration, LogeSoft [40] was used. In the process of modeling the RCM experiments, the effects of the compression phase and heat loss to the wall were modeled using the variable volume approach [41]. Using the isentropic law, effective volume histories were derived from non-reactive pressure traces obtained by replacing $\mathrm{O}_{2}$ with $\mathrm{N}_{2}$ in the mixtures, and were used as input in the Cantera solver [14].

\section{Results and discussion}

The consumption pathways of DMTHF predicted by the model are displayed in Fig. 5. Two conditions are presented: ST conditions ( $T=1200 \mathrm{~K}, \mathrm{p}=10 \mathrm{bar}$ and a fuel consumption of $20 \%$ ) (Fig. $5 \mathrm{~A}$ ) and the sampling condition in the $R C M\left(T_{c}=712 \mathrm{~K}, p=10 \mathrm{bar}\right.$, a sampling time of $30 \mathrm{~ms}$ and a fuel 
consumption of about 20\%.) (Fig. 5 B, C and D). The numbers depict the normalized rate of decomposition of each species in percent. The broken-line squares indicate species that were identified in the species measurements. At higher temperature, i.e $1200 \mathrm{~K}$, the reaction scheme is quite simple. First, $\mathrm{H}$-atom abstraction reactions mainly by $\mathrm{OH}$ convert 2,5-DMTHF into primary radicals and water. Due to the weak C-H BDE the favoured radical is DMTHF2J with more than $40 \%$ of the consumption rate followed by DMTHF1J and DMTHF3J with $23 \%$ and $17 \%$ respectively. Finally, the C-C bond dissociation leading to a 2-methytetrahydrofuran-5-yl radical and a methyl radical represent $10 \%$ of the conversion of the fuel. As discussed for the results of the sensitivity analysis result, this step is important in order to simulate accurately the 2,5-DMTHF reactivity at high temperatures. The primary radicals then mainly undergo beta-scission reactions leading to ring opening and other beta-scission reactions yielding smaller products.

Figure 5: (A) : Reaction pathway analysis of 2,5-DMTHF in ST conditions, at $T=1200 \mathrm{~K}, p=10$ bar and a fuel consumption of $20 \%$. (B), (C) and (D): Reaction pathway analysis of 2,5-DMTHF, for primary radical DMTHF1J (B), tertiary radical DMTHF2J (C), and secondary radical DMTHF3J (D), during a sampling experiment in a RCM of a stoichiometric mixture of 2,5DMTHF $/ \mathrm{O}_{2} / \mathrm{N}_{2}$ at $T_{c}=712 \mathrm{~K}, \mathrm{P}=10$ bar and sampling time of $30 \mathrm{~ms}$. Numbers by the arrows depict the normalized rate of decomposition (in \%) of the species. Broken-line squares indicate species that were experimentally identified.

In the low temperature range, the consumption of the fuel is in a large favour for the formation of DMTHF2J (82 \%). In contrast, the formation of DMTHF1J and DMTHF3J represent a cumulated ratio of only $15 \%$. By analysing the reaction pathway of 2,5-DMTHF, it is obvious that the lowtemperature branching that is typical for alkanes, i.e. through the formation of a ketohydroperoxide, is almost not relevant for 2,5-DMTHF. Indeed, the radical DMTHF2J is unable, after two $\mathrm{O}_{2}$ additions, to form a ketohydroperoxide described as Pathway I in Fig. 4. The ROP analysis shows that the steps forming a $\mathrm{HOOPOOH}$ radical represent an important contribution. Moreover, because the reactions of $\mathrm{HOOPOOH}$ end up with the formation of two $\mathrm{OH}$ radicals, the accurate description of its consumption is of importance. As depicted by the sensitivity analysis in the same conditions, the reactions leading to $\mathrm{HOOPOOH}$ promote the reactivity. It is possible to check validity of the description of the reactivity of radical DMTHF2J by comparing the experimental and simulated mole fraction profiles of the stable intermediates circled in Fig. 5.

Speciation experiments in the RCM allowed identification of 45 intermediates of the oxidation of 2,5-DMTHF in the low temperature regime, of which 35 could be quantified, some being at the trace level. Therefore, only the major species, i.e. with a maximal mole fraction higher than $50 \mathrm{ppm}$, were simulated. Their mole fraction profiles as a function of the sampling time are presented in Fig. 6 and 7. In these conditions, simulated ignition delay time $(43.98 \mathrm{~ms})$ is longer than the experimentally measured one $(42.8 \mathrm{~ms})$. Therefore, for the sake of clarity, the time of simulation is normalized to the experimental time of sampling. The good agreement displayed for these intermediates in Fig. 6 and 7 provides confidence in the fact that the model is able to accurately describe the fuel-specific reactivity and ignition of 2,5-DMTHF. 
Figure 6: Experimental (symbols) and simulated (lines) mole fraction profiles of fuel, CO and fuel specific species obtained for sampling conditions of a stoichiometric 2,5-DMTHF/ $\mathrm{O}_{2} / \mathrm{N}_{2}$ mixture: $T_{C}=712 \mathrm{~K}$ and $p_{T D C}=10 \mathrm{bar}$

Experimentally, cis- and trans-(2,5)-dimethytetrahydrofuran peaks were observed on the PorabondQ chromatograms, but could not be separated fully. However, the relative heights of both peaks did not vary as the fuel was consumed suggesting that both isomers have similar reactivity. The cis- form is less abundant in the initial fuel for reasons of steric effect, with a ratio of about $45 \%$. In the modeling work no distinction was made to distinguish the isomers of 2,5-DMTHF and consequently only the sum of the mole fraction profile for both cis- and trans-2,5-DMTHF is shown in Fig. 6 . Up to a sampling time of $28 \mathrm{~ms}$, the simulated mole fraction of 2,5-DMTHF is in excellent agreement with the experimental data. Nevertheless, at sampling times closer to the ignition event the consumption of 2,5-DMTHF is slightly overestimated. An explanation for this discrepancy could be that during the sampling process unreactive gases from the crevice are also captured in the sampling canister, resulting in a mild dilution of the samples. The mole fraction profiles for the fuel-specific stable intermediates are also depicted in Fig. 6. 3-hexen-3-one can be formed during the low temperature pathway of the DMTH3J radical. After this radical is added to $\mathrm{O}_{2}$ and undergoes internal isomerization, beta-scission (ring opening) of the hydroperoxyalkyl radical ( $\mathrm{QOOH})$ and subsequent bond scission within the hydroperoxyl group can yield the hex-3-en-2-one and $\mathrm{OH}$. The formation of hexa-2,5-dione follows the same reaction chain with the difference that it is originating from the DMTHF2J radical. 2,6-dimethyl-1,3-diox-4-ene is a cyclic compound with two oxygen atoms within a six-membered cycle which is formed after the addition of DMTHF2J on $\mathrm{O}_{2}$, an isomerization, and a structural rearrangement giving a $\dot{O H}$ radical. The steps leading to the dioxene formation from a cyclic ether were also observed during the oxidation of THF [4]. Finally, the formation of dimethyldihydrofurans is expected, with amounts comparable to the major other species detected, as in the case of dihydrofuran formation during THF oxidation [4]. Unfortunately, as in the study of MTHF [6], the retention times of dimethyldihydrofurans are similar to those of DMTHF, the fuel. Moreover, the large mole fraction of the fuel leads to a large peak on the chromatogram hiding the peaks of dimethyldihydrofurans, therefore unabling the quantification of these products.

Figure 7: Experimental (symbols) and simulated (lines) mole fraction profiles of stable intermediate species obtained for sampling conditions of a stoichiometric 2,5-DMTHF/O $/ \mathrm{N}_{2}$ mixture: $T \mathrm{C}=712 \mathrm{~K}$ and $p_{T D C}=10 \mathrm{bar}$

Figure 7 displays experimental and modelled mole fraction profiles for species with less than 6 carbon atoms. Among the most abundant of these intermediates, methylvinylketone is a product of the beta-scission reaction of the 2,5-hexanedion-3-yl radical, which itself yields from 2,5-hexadione by an $\mathrm{H}$-atom abstraction. Propene together with the acetonyl radical are products of the betascission of the favoured primary radical DMTHF2J. The large overestimation of its mole fraction for sampling times longer than $30 \mathrm{~ms}$ could indicate that the reaction rate calculated by Simmie [3] is overestimated. However, it is possible that not all reactions consuming DMTHF2J have been taken into account in the modeling work. The model however correctly estimates methyloxiran, an oxidation product of propene. The model also accurately reproduces the relative mole fraction profile of formaldehyde originating from secondary reactions present in the base mechanism. Methanol is mostly formed by an $\mathrm{H}$-atom abstraction from 2,5-DMTHF by the $\mathrm{CH}_{3} \mathrm{O}$ radical. The methyl radical is abundant in the reacting mixture for temperatures higher than $1000 \mathrm{~K}$ due to the $\mathrm{C}$ $\mathrm{C}$ bond breaking reaction of 2,5-DMTHF giving methyl radical and the 2-methyltetrahydrofuran-5-yl 
(R5MTHF) radical. $\mathrm{CH}_{3} \dot{\mathrm{O}}$ is formed mainly by the reaction $\dot{\mathrm{C}} \mathrm{H}_{3}+\mathrm{HO}_{2}=\mathrm{CH}_{3} \dot{\mathrm{O}}+\dot{\mathrm{O}} \mathrm{H}$. 2-Butenal originates from 2,6-dimethyl-1,3-diox-4-ene through an $\mathrm{H}$-atom abstraction reaction by $\mathrm{OH}$ and $\mathrm{HO}_{2}$ radicals followed by a ring opening beta-scission reaction. The product also undergoes a betascission that gives 2-butenal and $\dot{\mathrm{C}} \mathrm{H}_{2} \mathrm{CHO}$ radical.

The sampling experiments are conducted in one condition of temperature and pressure. In order to further investigate the behaviour of 2,5-DMTHF, ignition delay times ranging from $80 \mu$ s to $105 \mathrm{~ms}$ were measured in the two facilities. In the ST, at 10 and 20 bar, a deviation from Arrhenius dependence of the ignition delay is observed at the lowest temperatures. This is not observed at 40 bar, but could be possible at temperatures higher than $1250 \mathrm{~K}$. In the RCM, such a deviation is also seen between 750 and $850 \mathrm{~K}$, mostly at 10 and 15 bar. The model accurately reproduces this behavior.

Figure 8: Comparison between simulated (lines) and experimental (full symbols) delay times of stoichiometric 2,5DMTHF/O $\mathrm{O}_{2}$ /inert mixture. (A): shock tube experiments. (B): rapid compression machine; open symbols : experimental first stage ignition delay; dashed lines : simulated first stage ignition.

The experimental and simulated IDT are reported in Fig. 8. A good agreement between experiments and modeling is found for the complete range of temperature and the simulations are able to reflect the effect of pressure on the IDTs. In addition, the model is able to replicate the first stage ignition delays. In Fig. 3, experimental and simulated pressure profiles in RCM conditions are compared for a stoichiometric mixture of $2,5-\mathrm{DMTHF} / \mathrm{O}_{2} / \mathrm{N}_{2}$ at $\mathrm{T}_{\mathrm{C}}=712 \mathrm{~K}$ and $\mathrm{p}_{\mathrm{TDC}}=10 \mathrm{bar}$.

At these conditions, the pressure rise associated with first-stage ignition is gradual and total ignition delay time is reproducible, which eliminates an explanation of the gradual rise of pressure by a preignition (cf. Fig. 3). Indeed, as shown by Büttgen et al. [42], the occurrence of pre-ignition is not a repeatable phenomenon. Moreover, this behaviour has been also observed for other cyclic ethers as THF and 2-MTHF [4,5], or for unsaturated species [43]. The kinetics of the oxidation of 2,5-DMTHF explain this phenomenon. The branching ratio between $\mathrm{RO} 2=\mathrm{QOOH}$ and $\mathrm{RO} 2=$ unsaturated product $+\mathrm{HO} 2$ depicted in fig. 5 at $700 \mathrm{~K}$ remains similar at $850 \mathrm{~K}$ for 2,5-DMTHF. To the contrary, in the case of alkanes this branching widely tends to weigh in favour of the reaction $\mathrm{RO} 2=$ alkene + $\mathrm{HO} 2$ when the temperature goes from 700 to $850 \mathrm{~K}$ and leads to a reduction of the reactivity depicted by the NTC. For 2,5-DMTHF, this diminution do not occur, producing a constant and slow consumption of the fuel until the total ignition, justifying that no NTC is detected. This global behaviour is accurately reflected by the model (Figs 6 and 8 ).

In order to highlight the influent reactions involved in the ignition of 2,5-DMTHF ignition, a bruteforce sensitivity analysis was performed. The results of the brute-force analysis on the ignition delays are displayed in Fig. 9 for conditions relevant to both RCM and shock-tube experiments.

In Fig. 9, the sensitivity coefficient, $\sigma_{i}$, for total ignition delay time of a reaction $i$ is defined as:

$$
\sigma_{i}=\log \left(\tau_{i}^{+} / \tau_{i}^{-}\right) /(\log (2.0 / 0.5))
$$

Where $\tau_{i}^{+}$is the total ignition delay calculated with a factor-of-two increase in the reaction-rate coefficient of reaction $i\left(k_{i}\right)$, and $\tau_{i}^{-}$is the ignition delay calculated with a factor-of-two decrease in $k_{i}$. A positive $\sigma_{i}$ indicates an overall inhibiting effect on reactivity and vice versa. 
Figure 9: Brute-force sensitivity analysis on the ignition delay times of 2,5- DMTHF/O $/ 2$ inert mixtures at 20 bar and $700 \mathrm{~K}$ and $1200 \mathrm{~K}$.

The reaction pathway in Fig. 5 shows that DMTHF is mostly consumed through the formation of DMTHF2J: $82 \%$ at $712 \mathrm{~K}, 43 \%$ at $1200 \mathrm{~K}$. The sensitivity analysis shows that the consumption of DMTHF by DMTHF $+\mathrm{HO}_{2}=$ DMTHF2 $\mathrm{J}+\mathrm{H}_{2} \mathrm{O}_{2}$ substantially enhances the reactivity at $700 \mathrm{~K}$ for two reasons: As the temperature increases, the rate of hydrogen peroxide decomposition accelerates until it begins to provide significant chain branching, producing two $\mathrm{OH}$ radicals for each $\mathrm{H}_{2} \mathrm{O}_{2}$ species consumed leading to total ignition. Then, DMTHF2J is able to form OOOQOOH radicals (cf. Fig. 5), which conversion gives here again two OH radicals. To the contrary, the reaction DMTHF2O2J = $\mathrm{DMTHFX}+\mathrm{HO}_{2}$ is a reaction of chain propagation producing only one hydroperoxyl radical and the sensitivity analysis reveals a strong reactivity inhibiting effect for this reaction. Further low temperature reactivity steps of radical DMTHF2J exhibit noticeable negative sensitivity coefficient, such as the isomerization reaction leading to the 2-hydroperoxy-2,5-dimethyltetrahydrofur-4-yl radical (DMTHF2O2H4J). The reactions forming an unsaturated compound, such as 2-methylene-5methyl-tetrahydrofuran (DMTHF1X) or 2,5-dimethyl-2,3-dihydrofuran (DMTHF2X) competing with this reaction show a positive coefficient.

In the high-temperature regime $(T=1200 \mathrm{~K})$, the reactivity is led by reactions involving methyl radicals. Methyl radicals are indeed quickly formed (Fig. 5) through the unimolecular decomposition reaction that yields the 2-methyltetrahydrofuran-5-yl radical R5MTHF. Consequently, the reactions of $\dot{\mathrm{CH}}_{3}$ with $\mathrm{O}_{2}$ and $\mathrm{HO}_{2}$, producing an $\dot{\mathrm{OH}}$ radical promote the reactivity, whilst the termination reactions $\dot{\mathrm{CH}}_{3}+\mathrm{HO}_{2}=\mathrm{CH}_{4}+\mathrm{O}_{2}$ and $2 \dot{\mathrm{CH}}_{3}(+\mathrm{M})=\mathrm{C}_{2} \mathrm{H}_{6}(+\mathrm{M})$ tend to increase the IDT.

\section{Conclusions}

In this first kinetic study on the oxidation of 2,5-DMTHF under engine relevant conditions, ignition delay times are presented measured with two facilities to cover a wide range of temperature. In the PCFC high pressure shock tube ignition delays of stoichiometric 2,5-DMTHF/ $\mathrm{O}_{2} / \mathrm{N}_{2}$ mixtures were acquired for pressures of 10,20, and 40 bar and temperatures between 860 and 1320 . The low-tointermediate temperature ignition delay times of stoichiometric 2,5-DMTHF/ $\mathrm{O}_{2} /$ inert mixtures were measured in the U-Lille RCM for pressures 10, 15 and, 20 bar and temperatures ranging from 660 to $880 \mathrm{~K}$. From these results, no clear NTC was observed but only a deviation from Arrhenius behaviour. To predict the reactivity of 2,5-DMTHF, a kinetic model was developed including the reaction classes relevant to low and high temperature and adopting the previous discussions from similar works on THF and 2-MTHF.

Since the thermodynamic data of species involved in the low temperature branching are of importance for reliable modeling, they were calculated with a high-level quantum mechanics method, i.e. G4. The validity of the model was extended to the predictability of the mole fraction profiles of the major stable intermediates present in the reactive mixture during the ignition delay. Experimental data were obtained by sampling the reactive stoichiometric 2,5-DMTHF/O $\mathrm{O}_{2} / \mathrm{N}_{2}$ mixture in the combustion chamber of the U.Lille RCM at $T_{C}=712 \mathrm{~K}$ and $\mathrm{P}=10$ bar for different sampling times between $t_{T D C}$ and the main ignition event. 45 species were identified among which 35 could be quantified with a GC-MS-FID. The most abundant stable intermediates with a mole fraction higher than $50 \mathrm{ppm}$ were used as validation target. An excellent agreement was obtained between simulated and experimental data. 
Sensitivity analysis shows a promoting influence of methyl radicals at $1200 \mathrm{~K}$ due to the $\mathrm{C}-\mathrm{C}$ bond dissociation from 2,5-DMTHF producing the 2-methyltetrahydrofuran-5-yl radical and a methyl radical. At lower temperatures, the reactivity is led by the competition between reactions producing two $\mathrm{OH}$ radicals in the low temperature branching and the reactions consuming the species involved in this $\mathrm{OH}$ production channel. A reaction pathway analysis indicates that in the low temperature range the production of the radical DMTHF $2 \mathrm{~J}$ accounts for more than $4 / 5$ of the decomposition of DMTHF. The addition of the DMTHF2J radical on a tertiary carbon on $\mathrm{O}_{2}$ cannot lead to the formation of ketohydroperoxides, kinetically favoured product in the low temperature branching. Because of this particularity the model considers reactions commonly excluded from kinetic modeling, as the isomerization reactions $\mathrm{OOQOOH}=\mathrm{HOOPOOH}$ and the further reactions of HOOPOOHradicals. More generally, the pathway analysis gives an overview of this oxidation process of 2,5-DMTHF and elucidates the formation of experimentally observed fuel-specific intermediates.

\section{Acknowledgement}

Part of this work was performed as part of the Cluster of Excellence "Tailor-Made Fuels from Biomass" (EXC 236), which is funded by the Excellence Initiative by the German federal and state governments to promote science and research at German universities. The PC2A group thanks the Région "Hauts de France", the Ministère de l'Enseignement Supérieur et de la Recherche (CPER Climibio), and the European Fund for Regional Economic Development, as well as acknowledges funding from the Université de Lille through the Lignofuel "Internationalisation" project.

\section{Supplementary materials}

Experimental ignition delay times and conditions in a shock tube and a rapid compression machine

Experimental mole fraction profiles for identified and quantified species in a RCM

Dictionary for species in the sub-model for DMTHF

Detailed kinetic model: mechanism

Detailed kinetic model: thermodynamic data

Non-reactive pressure profiles (RCM)

Information about the calculated thermodynamic data

\section{Bibliography}

[1] M. J. Climent, A. Corma, S. Iborra, Conversion of biomass platform molecules into fuel additives and liquid hydrocarbon fuels, Green Chem. 16 (2014) 516-547. doi:10.1039/C3GC41492B.

[2] Z. Gao, C. Li, G. Fan, L. Yang, F. Li, Nitrogen-doped carbon-decorated copper catalyst for highly efficient transfer hydrogenolysis of 5-hydroxymethylfurfural to convertibly produce 2,5dimethylfuran or 2,5-dimethyltetrahydrofuran, Appl. Catal. B Environ. 226 (2018) 523-533. doi:10.1016/j.apcatb.2018.01.006.

[3] J.M. Simmie, Kinetics and Thermochemistry of 2,5-Dimethyltetrahydrofuran and Related Oxolanes: Next Next-Generation Biofuels, J. Phys. Chem. A. 116 (2012) 4528-4538. doi:10.1021/jp301870w.

[4] G. Vanhove, Y. Yu, M.A. Boumehdi, O. Frottier, O. Herbinet, P.-A. Glaude, F. Battin-Leclerc, Experimental Study of Tetrahydrofuran Oxidation and Ignition in Low-Temperature Conditions, Energy Fuels. 29 (2015) 6118-6125. doi:10.1021/acs.energyfuels.5b01057. 
[5] Y. Fenard, A. Gil, G. Vanhove, H.-H. Carstensen, K.M. Van Geem, P.R. Westmoreland, O. Herbinet, F. Battin-Leclerc, A model of tetrahydrofuran low-temperature oxidation based on theoretically calculated rate constants, Combust. Flame. 191 (2018) 252-269.

doi:10.1016/j.combustflame.2018.01.006.

[6] Y. Fenard, M.A. Boumehdi, G. Vanhove, Experimental and kinetic modeling study of 2methyltetrahydrofuran oxidation under engine-relevant conditions, Combust. Flame. 178 (2017) 168-181. doi:10.1016/j.combustflame.2017.01.008.

[7] R. De Bruycker, L.-S. Tran, H.-H. Carstensen, P.-A. Glaude, F. Monge, M.U. Alzueta, F. BattinLeclerc, K.M. Van Geem, Experimental and modeling study of the pyrolysis and combustion of 2-methyl-tetrahydrofuran, Combust. Flame. 176 (2017) 409-428. doi:10.1016/j.combustflame.2016.11.017.

[8] R. Tripathi, C. Lee, R.X. Fernandes, H. Olivier, H.J. Curran, S. Mani Sarathy, H. Pitsch, Ignition characteristics of 2-methyltetrahydrofuran: An experimental and kinetic study, Proc. Combust. Inst. 36 (2017) 587-595. doi:10.1016/j.proci.2016.07.103.

[9] S.M. Sarathy, C.K. Westbrook, M. Mehl, W.J. Pitz, C. Togbe, P. Dagaut, H. Wang, M.A. Oehlschlaeger, U. Niemann, K. Seshadri, P.S. Veloo, C. Ji, F.N. Egolfopoulos, T. Lu, Comprehensive chemical kinetic modeling of the oxidation of 2-methylalkanes from C7 to C20, Combust. Flame. 158 (2011) 2338-2357. doi:10.1016/j.combustflame.2011.05.007.

[10] H.J. Curran, P. Gaffuri, W.J. Pitz, C.K. Westbrook, A Comprehensive Modeling Study of nHeptane Oxidation, Combust. Flame. 114 (1998) 149-177. doi:10.1016/S0010-2180(97)002824.

[11] K. Zhang, C. Banyon, J. Bugler, H.J. Curran, A. Rodriguez, O. Herbinet, F. Battin-Leclerc, C. $B^{\prime} C h i r, K . A$. Heufer, An updated experimental and kinetic modeling study of $n$-heptane oxidation, Combust. Flame. 172 (2016) 116-135. doi:10.1016/j.combustflame.2016.06.028.

[12] H. Minwegen, U. Burke, K.A. Heufer, An experimental and theoretical comparison of C3-C5 linear ketones, Proc. Combust. Inst. 36 (2017) 561-568. doi:10.1016/j.proci.2016.05.050.

[13] http://shepherd.caltech.edu/EDL/public/cantera/html/SD_Toolbox/, (n.d.).

[14] D. G. Goodwin, H. K. Moat, R. L. Speth, Cantera: An object-oriented software toolkit 250 for chemical kinetics, thermodynamics, and transport processes, Httpwwwcanteraorg Version 220. (2015).

[15] S.M. Burke, U. Burke, R. Mc Donagh, O. Mathieu, I. Osorio, C. Keesee, A. Morones, E.L. Petersen, W. Wang, T.A. DeVerter, M.A. Oehlschlaeger, B. Rhodes, R.K. Hanson, D.F. Davidson, B.W. Weber, C.-J. Sung, J. Santner, Y. Ju, F.M. Haas, F.L. Dryer, E.N. Volkov, E.J.K. Nilsson, A.A. Konnov, M. Alrefae, F. Khaled, A. Farooq, P. Dirrenberger, P.-A. Glaude, F. Battin-Leclerc, H.J. Curran, An experimental and modeling study of propene oxidation. Part 2: Ignition delay time and flame speed measurements, Combust. Flame. 162 (2015) 296-314. doi:10.1016/j.combustflame.2014.07.032.

[16] Y. Yu, G. Vanhove, J.F. Griffiths, S. De Ferrières, J.-F. Pauwels, Influence of EGR and Syngas Components on the Autoignition of Natural Gas in a Rapid Compression Machine: A Detailed Experimental Study, Energy Fuels. 27 (2013) 3988-3996. doi:10.1021/ef400336x.

[17] D. Lee, S. Hochgreb, Rapid Compression Machines: Heat Transfer and Suppression of Corner Vortex, Combust. Flame. 114 (1998) 531-545. doi:10.1016/S0010-2180(97)00327-1.

[18] J.T. Scanlon, D.E. Willis, Calculation of Flame Ionization Detector Relative Response Factors Using the Effective Carbon Number Concept, J. Chromatogr. Sci. 23 (1985) 333-340. doi:10.1093/chromsci/23.8.333.

[19] Y. Li, C.-W. Zhou, K.P. Somers, K. Zhang, H.J. Curran, The oxidation of 2-butene: A high pressure ignition delay, kinetic modeling study and reactivity comparison with isobutene and 1-butene, Proc. Combust. Inst. 36 (2017) 403-411. doi:10.1016/j.proci.2016.05.052.

[20] E.R. Ritter, J.W. Bozzelli, THERM: Thermodynamic property estimation for gas phase radicals and molecules, Int. J. Chem. Kinet. 23 (n.d.) 767-778. doi:10.1002/kin.550230903. 
[21] S.W. Benson, J.H. Buss, Additivity Rules for the Estimation of Molecular Properties. Thermodynamic Properties, J. Chem. Phys. 29 (1958) 546-572. doi:10.1063/1.1744539.

[22] O.V. Dorofeeva, Ideal gas thermodynamic properties of oxygen heterocyclic compounds Part 1. Three-membered, four-membered and five-membered rings, Thermochim. Acta. 194 (1992) 946. doi:10.1016/0040-6031(92)80002-E.

[23] J. Bugler, K.P. Somers, E.J. Silke, H.J. Curran, Revisiting the Kinetics and Thermodynamics of the Low-Temperature Oxidation Pathways of Alkanes: A Case Study of the Three Pentane Isomers, J. Phys. Chem. A. 119 (2015) 7510-7527. doi:10.1021/acs.jpca.5b00837.

[24] L.A. Curtiss, P.C. Redfern, K. Raghavachari, Gaussian-4 theory, J. Chem. Phys. 126 (2007) 084108. doi:10.1063/1.2436888.

[25] M. Frisch, G. Trucks, H.B. Schlegel, G.E. Scuseria, M.A. Robb, J.R. Cheeseman, G. Scalmani, V. Barone, B. Mennucci, Ga. Petersson, others, Gaussian 09, revision a. 02, gaussian, Inc Wallingford CT. 200 (2009).

[26] L.A. Curtiss, P.C. Redfern, K. Raghavachari, Assessment of Gaussian-3 and density-functional theories on the G3/05 test set of experimental energies, J. Chem. Phys. 123 (2005) 124107. doi:10.1063/1.2039080.

[27] J.M. Simmie, K.P. Somers, Benchmarking Compound Methods (CBS-QB3, CBS-APNO, G3, G4, W1BD) against the Active Thermochemical Tables: A Litmus Test for Cost-Effective Molecular Formation Enthalpies, J. Phys. Chem. A. 119 (2015) 7235-7246. doi:10.1021/jp511403a.

[28] M. Saeys, M.-F. Reyniers, G.B. Marin, V. Van Speybroeck, M. Waroquier, Ab Initio Calculations for Hydrocarbons: Enthalpy of Formation, Transition State Geometry, and Activation Energy for Radical Reactions, J. Phys. Chem. A. 107 (2003) 9147-9159. doi:10.1021/jp021706d.

[29] U. Burke, J. Beeckmann, W.A. Kopp, Y. Uygun, H. Olivier, K. Leonhard, H. Pitsch, K.A. Heufer, A comprehensive experimental and kinetic modeling study of butanone, Combust. Flame. 168 (2016) 296-309. doi:10.1016/j.combustflame.2016.03.001.

[30] A. Ghysels, T. Verstraelen, K. Hemelsoet, M. Waroquier, V. Van Speybroeck, TAMkin: A Versatile Package for Vibrational Analysis and Chemical Kinetics, J. Chem. Inf. Model. 50 (2010) 1736-1750. doi:10.1021/ci100099g.

[31] A. Kéromnès, W.K. Metcalfe, K.A. Heufer, N. Donohoe, A.K. Das, C.-J. Sung, J. Herzler, C. Naumann, P. Griebel, O. Mathieu, M.C. Krejci, E.L. Petersen, W.J. Pitz, H.J. Curran, An experimental and detailed chemical kinetic modeling study of hydrogen and syngas mixture oxidation at elevated pressures, Combust. Flame. 160 (2013) 995-1011. doi:10.1016/j.combustflame.2013.01.001.

[32] W.K. Metcalfe, S.M. Burke, S.S. Ahmed, H.J. Curran, A Hierarchical and Comparative Kinetic Modeling Study of C1 - C2 Hydrocarbon and Oxygenated Fuels, Int. J. Chem. Kinet. 45 (n.d.) 638-675. doi:10.1002/kin.20802.

[33] N. Atef, G. Kukkadapu, S.Y. Mohamed, M.A. Rashidi, C. Banyon, M. Mehl, K.A. Heufer, E.F. Nasir, A. Alfazazi, A.K. Das, C.K. Westbrook, W.J. Pitz, T. Lu, A. Farooq, C.-J. Sung, H.J. Curran, S.M. Sarathy, A comprehensive iso-octane combustion model with improved thermochemistry and chemical kinetics, Combust. Flame. 178 (2017) 111-134. doi:10.1016/j.combustflame.2016.12.029.

[34] H.K. Chakravarty, R.X. Fernandes, Reaction Kinetics of Hydrogen Abstraction Reactions by Hydroperoxyl Radical from 2-Methyltetrahydrofuran and 2,5-Dimethyltetrahydrofuran, J. Phys. Chem. A. 117 (2013) 5028-5041. doi:10.1021/jp402801c.

[35] F. Dubnikova, A. Lifshitz, Molecular hydrogen elimination from 2,5-dihydrofuran, 2,3dihydrofuran, and 2-methyl-2,5-dihydrofuran: Quantum chemical and kinetics calculations, Int. J. Chem. Kinet. 33 (n.d.) 685-697. doi:10.1002/kin.1065.

[36] F. Battin-Leclerc, Detailed chemical kinetic models for the low-temperature combustion of hydrocarbons with application to gasoline and diesel fuel surrogates, Prog. Energy Combust. Sci. 34 (2008) 440-498. doi:10.1016/j.pecs.2007.10.002. 
[37] A. Miyoshi, Molecular size dependent falloff rate constants for the recombination reactions of alkyl radicals with $\mathrm{O} 2$ and implications for simplified kinetics of alkylperoxy radicals, Int. J. Chem. Kinet. 44 (n.d.) 59-74. doi:10.1002/kin.20623.

[38] P.R. Parab, N. Sakade, Y. Sakai, R. Fernandes, K.A. Heufer, A Computational Kinetics Study on the Intramolecular Hydrogen Shift Reactions of Alkylperoxy Radicals in 2Methyltetrahydrofuran Oxidation, Int. J. Chem. Kinet. 49 (n.d.) 419-437. doi:10.1002/kin.21087.

[39] C.F. Goldsmith, W.H. Green, S.J. Klippenstein, Role of $\mathrm{O} 2+\mathrm{QOOH}$ in Low-Temperature Ignition of Propane. 1. Temperature and Pressure Dependent Rate Coefficients, J. Phys. Chem. A. 116 (2012) 3325-3346. doi:10.1021/jp210722w.

[40] LOGESoft, available at http://loge.se/Products/LOGE_Products.html, (n.d.).

[41] S. Tanaka, F. Ayala, J.C. Keck, A reduced chemical kinetic model for $\mathrm{HCCl}$ combustion of primary reference fuels in a rapid compression machine, Combust. Flame. 133 (2003) 467-481. doi:10.1016/S0010-2180(03)00057-9.

[42] R.D. Büttgen, T. Raffius, G. Grünefeld, H.-J. Koß, A. Heufer, High-speed imaging of the ignition of ethanol at engine relevant conditions in a rapid compression machine, Proc. Combust. Inst. (2018). doi:10.1016/j.proci.2018.05.001.

[43] R. Minetti, A. Roubaud, E. Therssen, M. Ribaucour, L.R. Sochet, The chemistry of pre-ignition of n-pentane and 1-pentene, Combust. Flame. 118 (1999) 213-220. doi:10.1016/S00102180(98)00151-5. 
THF

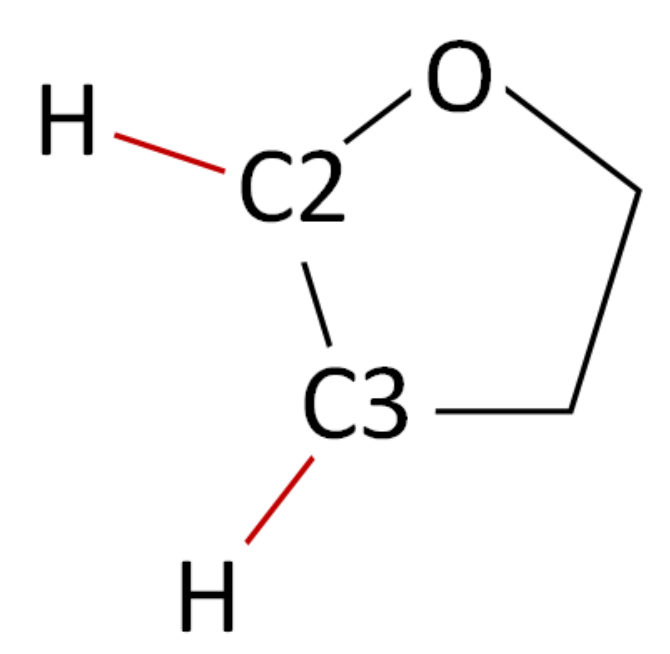

2-MTHF

I

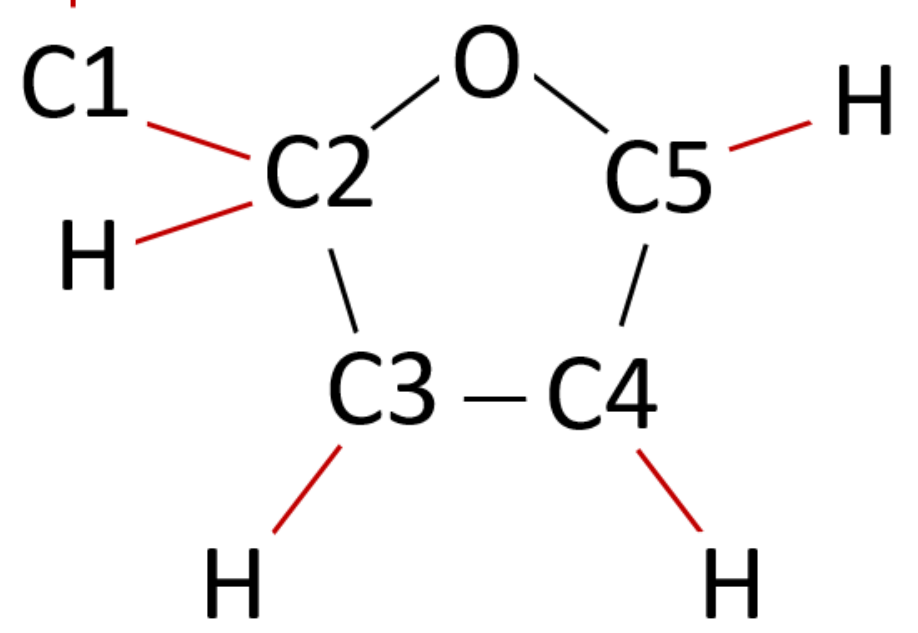

2,5-DMTHF

H

C1

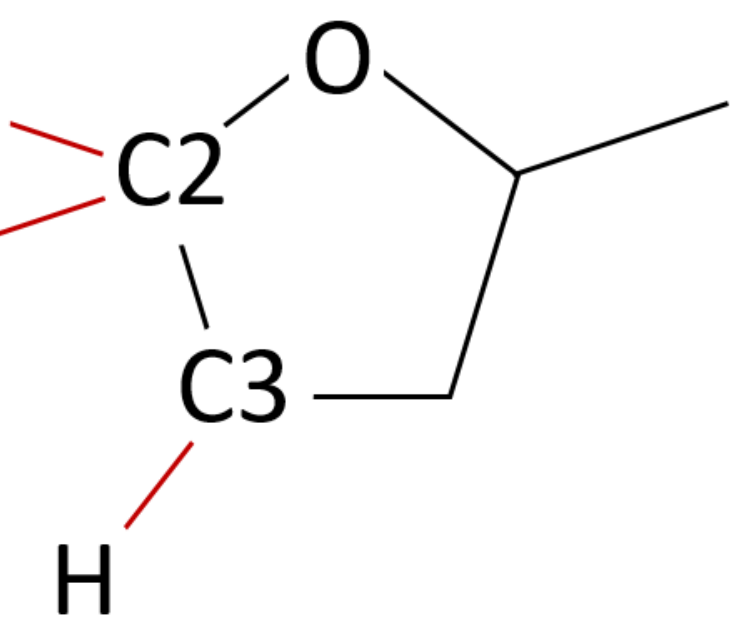

Bond dissociation energies comparison
$\mathrm{CH}_{2}-\mathrm{H}=430.9 \pm 1.5$
$\mathrm{CH}_{2}-\mathrm{H}=431.8 \pm 1.2$
$\mathrm{C} 2-\mathrm{H}=388.7 \pm 0.4$
$\mathrm{C} 2-\mathrm{H}=387.7 \pm 0.8$
$\mathrm{C} 3-\mathrm{H}=415.6 \pm 0.3$
$\mathrm{C} 3-\mathrm{H}=414.5 \pm 0.1$
$\mathrm{C} 3-\mathrm{H}=411.6 \pm 0.2$
$\mathrm{C} 4-\mathrm{H}=411.0 \pm 0.1$
$\mathrm{C} 2-\mathrm{H}=392.4 \pm 0.7$
$\mathrm{C} 5-\mathrm{H}=391.9 \pm 0.3$
$\mathrm{C}-\mathrm{CH}_{3}=361.6 \pm 2.4$
$\mathrm{C}-\mathrm{CH}_{3}=360.8 \pm 2.1$ 


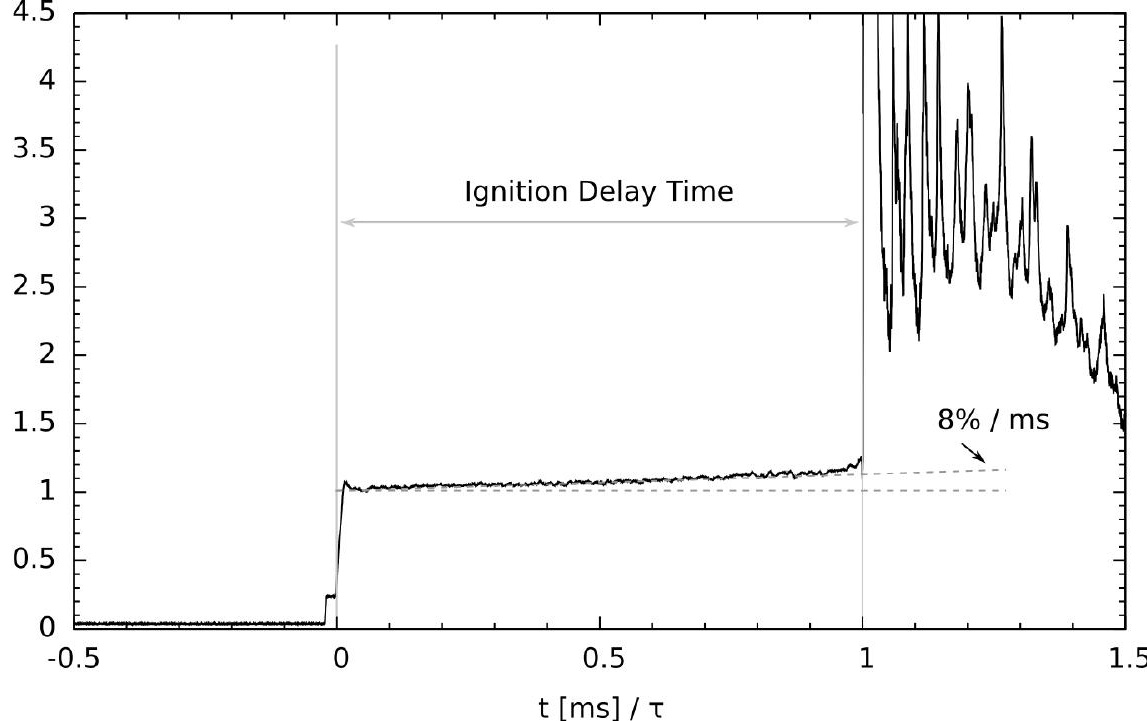




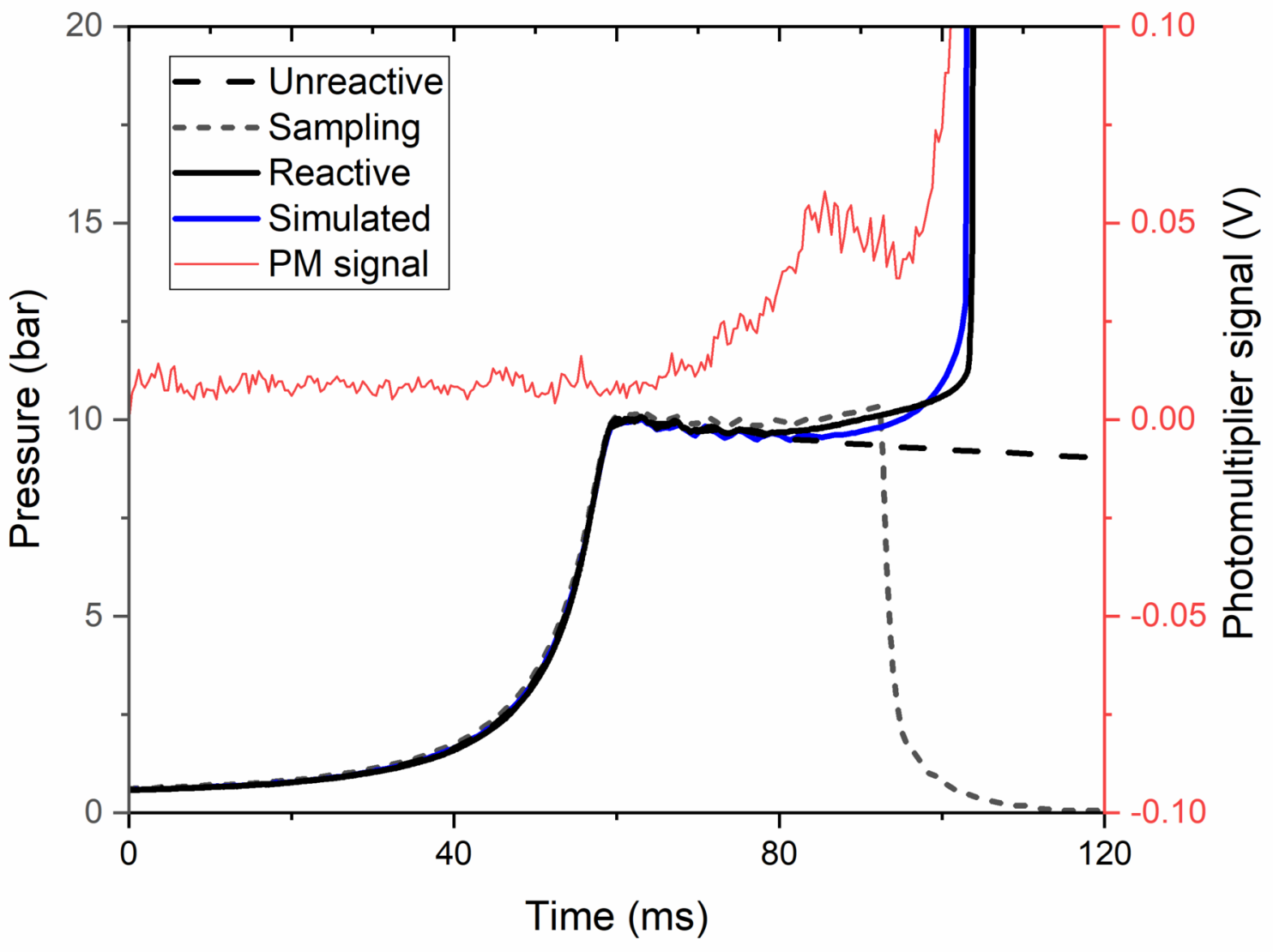




\section{Pathway I}

$\mathrm{RH} \longrightarrow \mathrm{R} \longrightarrow \mathrm{RO} \longrightarrow \mathrm{QOOH} \longrightarrow \mathrm{O} \longrightarrow$ Ketohydroperoxide $+\mathrm{OH} \longrightarrow \mathrm{OOOOH} \longrightarrow \mathrm{OH} \longrightarrow \mathrm{OH}$
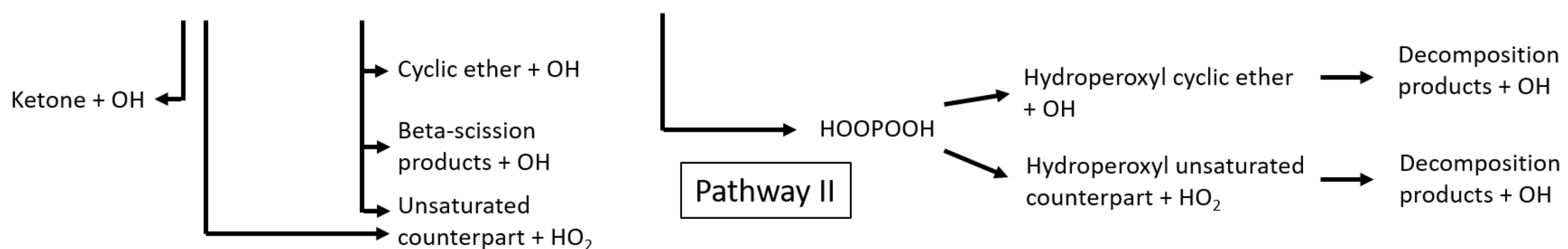


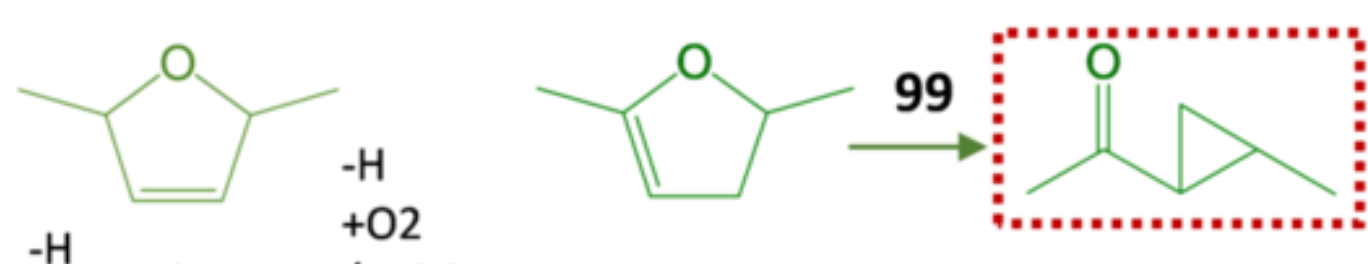

99 $\int_{-\mathrm{XH}}^{23}$

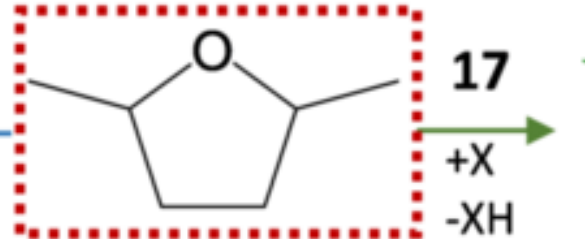

\begin{tabular}{l|l}
$+\mathrm{O} 2$ & 4 \\
$/ \mathrm{HO} 2$ &
\end{tabular}

.......................

$\downarrow 99$
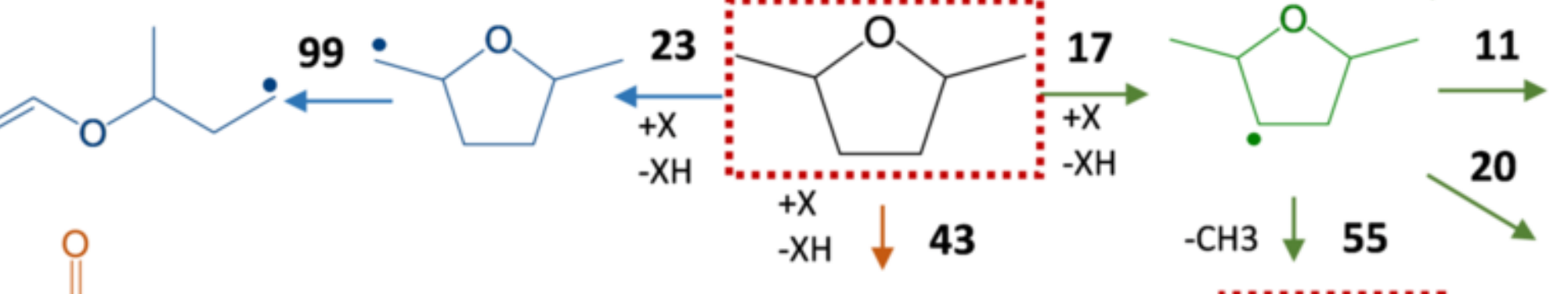

96
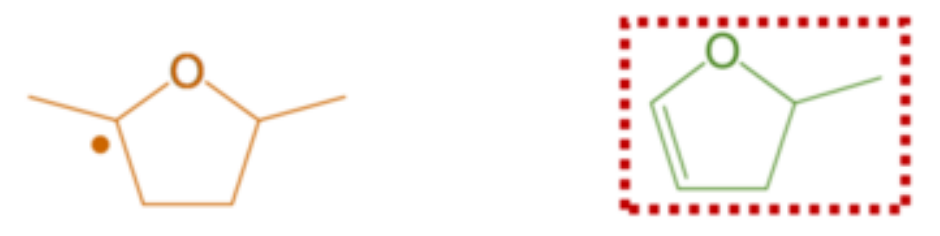

99

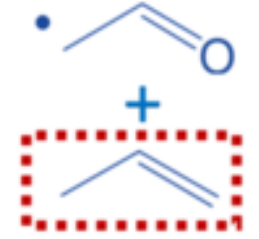

99

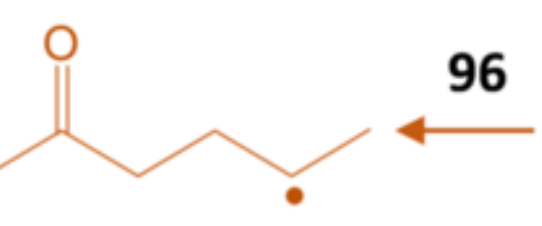

$\stackrel{54}{90}$
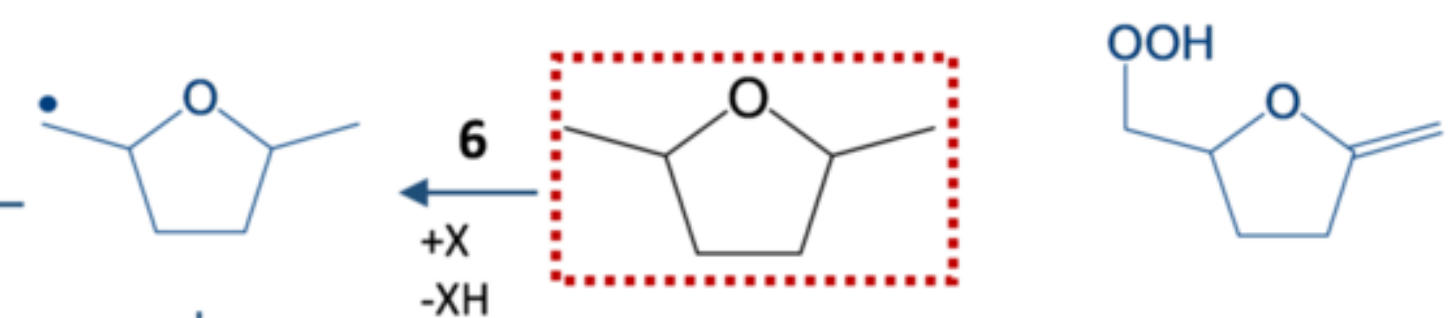

(B)

I<smiles>CC(=O)CCC(C)CCC(C)C(=O)OO</smiles>

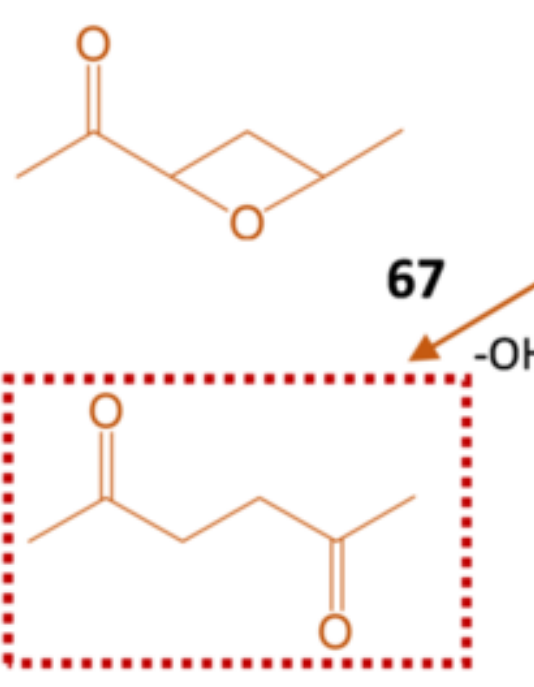

(C)<smiles>C1C[Te]C[Te]1</smiles>
${ }_{\mathrm{HOO}}^{\mathrm{O}}$

$33 \downarrow+02$
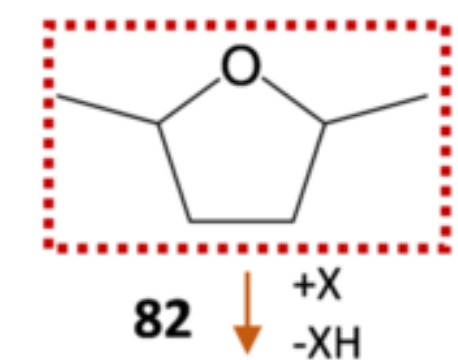

10<smiles>C1CC2CCC(C1)O2</smiles>

$$
83 \downarrow+0
$$<smiles>CC1(C)OC2CC3CC2CC31</smiles><smiles>[14CH3][14CH3]</smiles>

$+\mathrm{O} 2$
$-\mathrm{HO} 2$

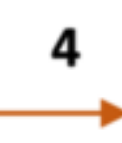

57

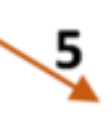

$\mathrm{OOH}$

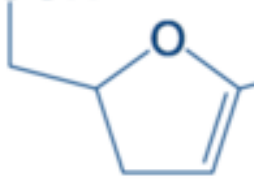



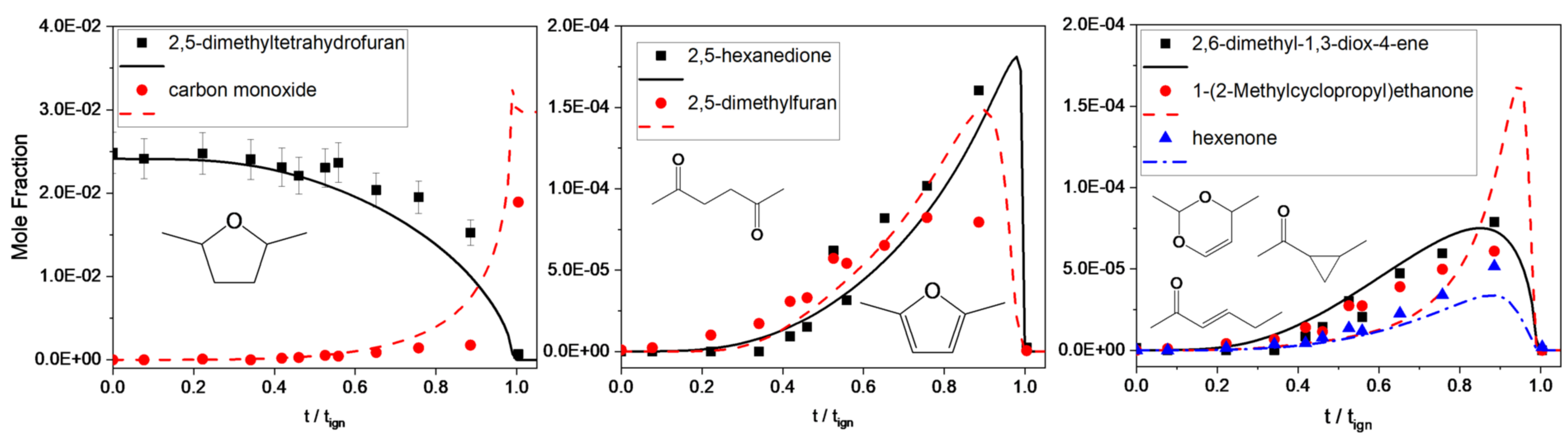


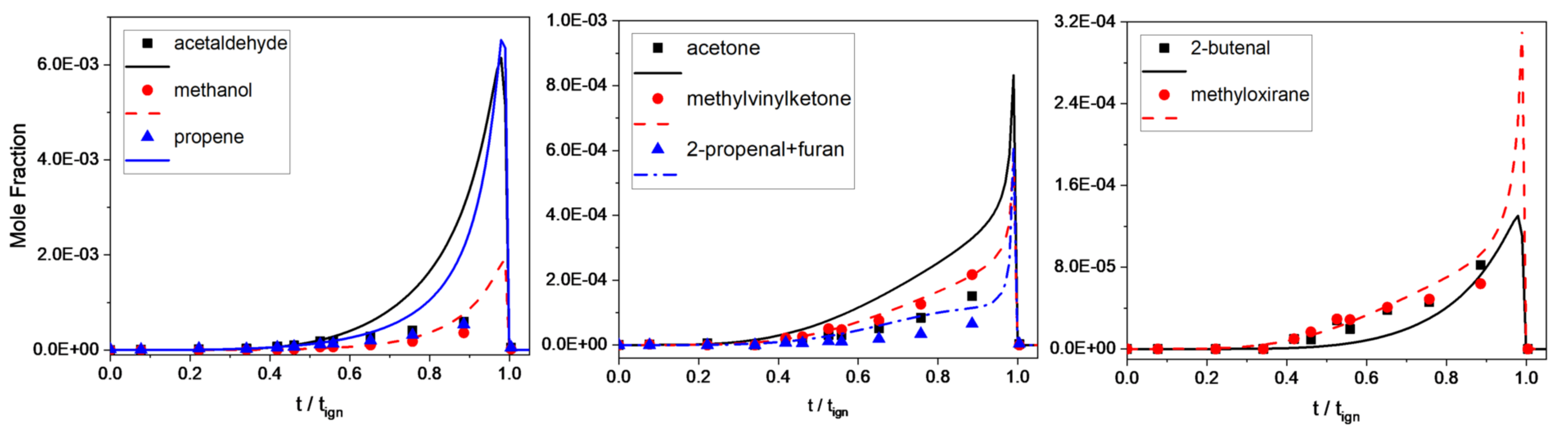




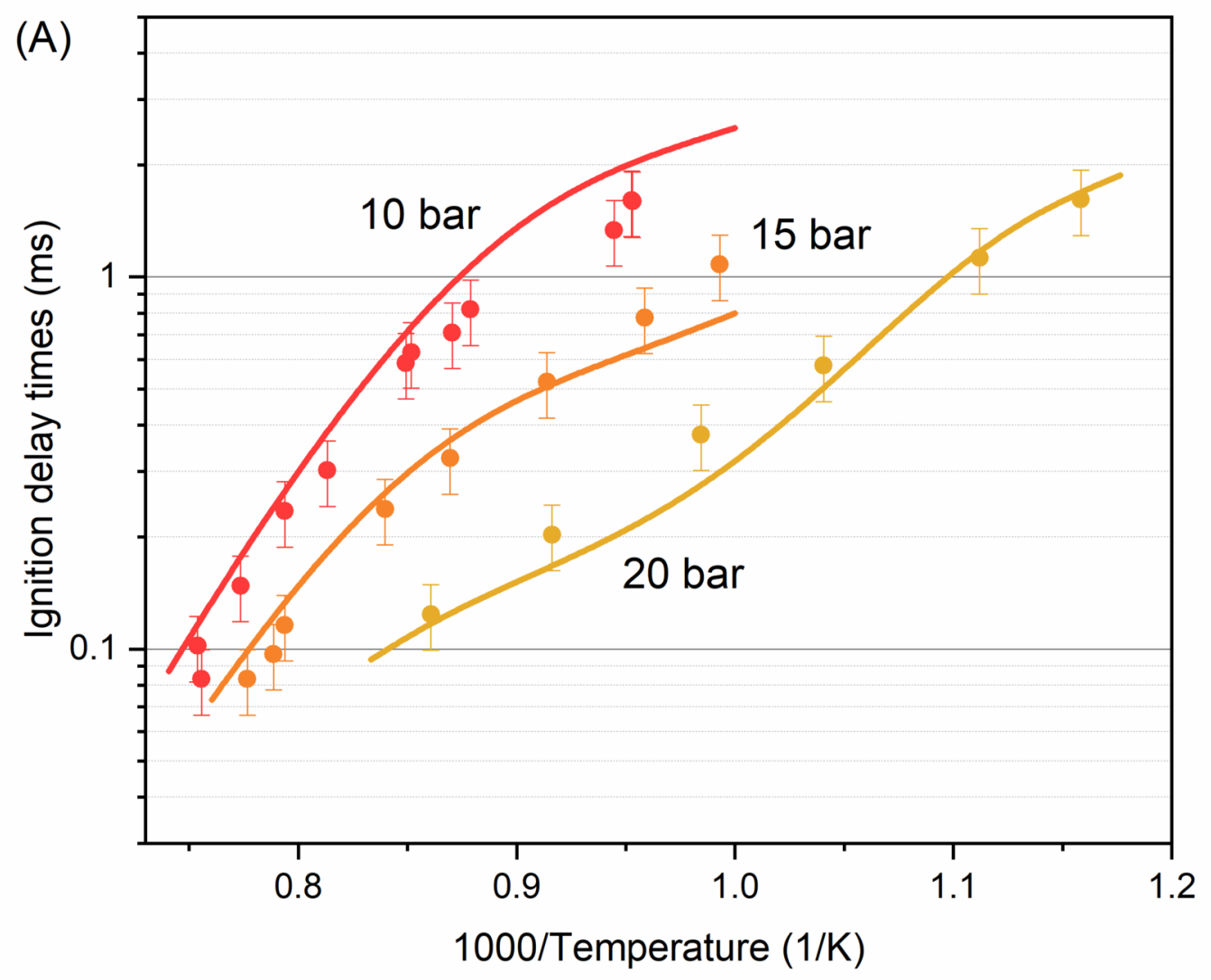




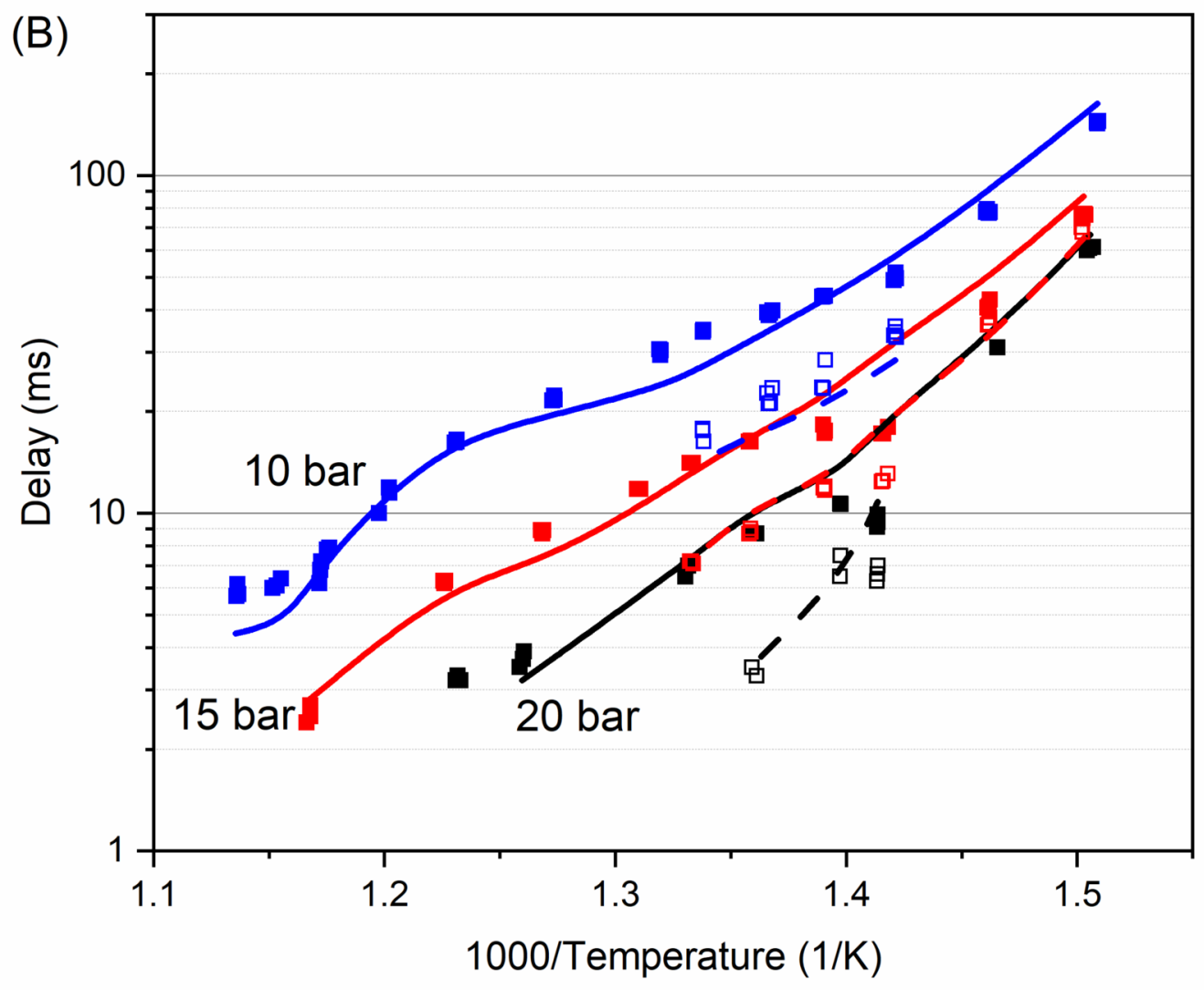



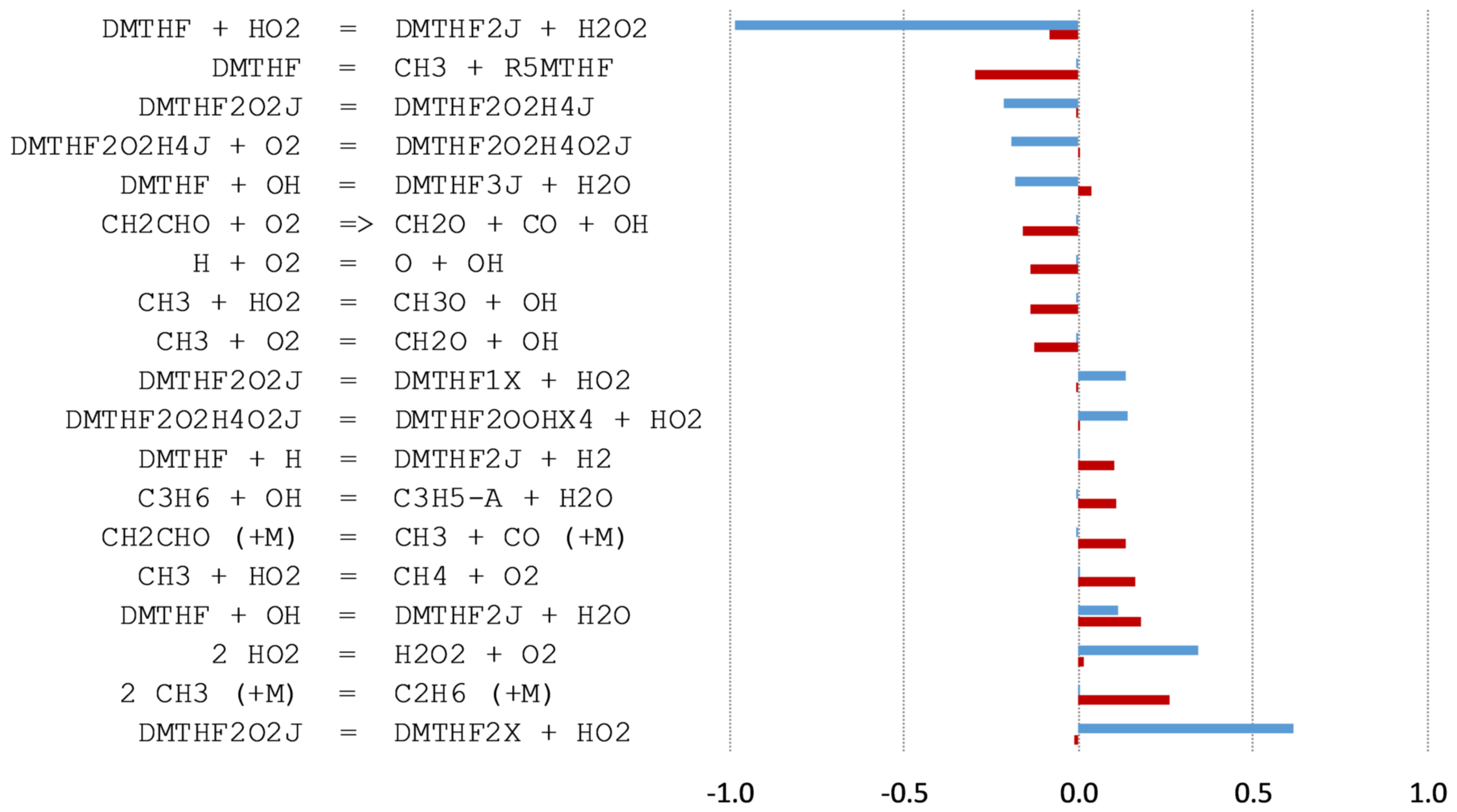